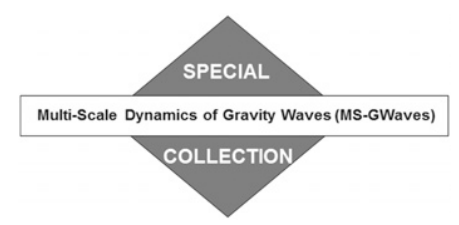

\title{
əIntercomparison of Gravity Waves in Global Convection-Permitting Models
}

\author{
Claudia Christine StePhan \\ Max Planck Institute for Meteorology, Hamburg, Germany \\ CORNELIA STRUBE \\ Forschungszentrum Jülich, Jülich, Germany \\ DANIEL KLOCKE \\ Hans-Ertel-Zentrum für Wetterforschung, Deutscher Wetterdienst, Offenbach, Germany \\ Manfred ERn, Lars Hoffmann, ANd Peter Preusse \\ Forschungszentrum Jülich, Jülich, Germany \\ HAUKE SCHMIDT \\ Max Planck Institute for Meteorology, Hamburg, Germany
}

(Manuscript received 14 February 2019, in final form 3 May 2019)

\begin{abstract}
Large uncertainties remain with respect to the representation of atmospheric gravity waves (GWs) in general circulation models (GCMs) with coarse grids. Insufficient parameterizations result from a lack of observational constraints on the parameters used in GW parameterizations as well as from physical inconsistencies between parameterizations and reality. For instance, parameterizations make oversimplifying assumptions about the generation and propagation of GWs. Increasing computational capabilities now allow GCMs to run at grid spacings that are sufficiently fine to resolve a major fraction of the GW spectrum. This study presents the first intercomparison of resolved GW pseudomomentum fluxes (GWMFs) in global convection-permitting simulations and those derived from satellite observations. Six simulations of three different GCMs are analyzed over the period of one month of August to assess the sensitivity of GWMF to model formulation and horizontal grid spacing. The simulations reproduce detailed observed features of the global GWMF distribution, which can be attributed to realistic GWs from convection, orography, and storm tracks. Yet the GWMF magnitudes differ substantially between simulations. Differences in the strength of convection may help explain differences in the GWMF between simulations of the same model in the summer low latitudes where convection is the primary source. Across models, there is no evidence for a systematic change with resolution. Instead, GWMF is strongly affected by model formulation. The results imply that validating the realism of simulated GWs across the entire resolved spectrum will remain a difficult challenge not least because of a lack of appropriate observational data.
\end{abstract}

D Denotes content that is immediately available upon publication as open access.

Corresponding author: Claudia Christine Stephan, claudia.stephan@mpimet.mpg.de

\section{Introduction}

Atmospheric gravity waves (GWs) play a key role in defining the large-scale global circulation and thermal structure of the middle and upper atmosphere, and they are important drivers of global atmospheric variability on various time scales. They are the main driver of the mesospheric summer to winter pole-to-pole circulation (Holton 1982, 1983) and the reason for the cold summer mesopause (Björn 1984). In the stratosphere, 
GWs affect the timing of the springtime transition from westerly to easterly winds with important consequences for the propagation and drag of planetary and synoptic waves (Scaife et al. 2002). They also contribute to the forcing of the Brewer-Dobson circulation and thus to the transport of trace gases like ozone and water vapor (Alexander and Rosenlof 1996). Convectively generated GWs are important for generating the quasi-biennial oscillation (QBO) in the tropics (Labitzke 2005; Marshall and Scaife 2009), which has a strong influence on troposphere-stratosphere exchanges of water vapor, ozone, and other gases (Baldwin et al. 2001), as well as remote effects on global circulation. Deep convective systems are a major source for GWs in the tropics and the summer midlatitudes (Pfister et al. 1993; McLandress et al. 2000; Preusse et al. 2001; Hoffmann and Alexander 2010; Choi et al. 2012). Other important tropospheric GW sources are regions of imbalanced flow near jets (e.g., O'Sullivan and Dunkerton 1995; Zhang 2004, Plougonven and Zhang 2014) and flow over orography (e.g., Lilly and Kennedy 1973; Dörnbrack et al. 1999; Eckermann and Preusse 1999; Jiang et al. 2004; Fritts et al. 2016).

We here present the first intercomparison of GW pseudomomentum fluxes (GWMFs) in global convectionpermitting simulations of three different state-of-the-art GCMs and those derived from satellite observations. Two simulations are performed with each model. The horizontal resolutions between each pair of simulations differ by a factor of 2 and range from 2.5 to $9 \mathrm{~km}$. The ensemble of six simulations gives us the opportunity to assess the systematic differences between the models and analyze the potential origins of these differences, which could, in principle, be tied to the numerical framework of the model (e.g., damping and diffusion) or explicitly be linked to GW sources (e.g., to the strength of convection in a simulation).

Because of their complex generation mechanisms and small scales, ranging from $O(10)$ to $O(1000) \mathrm{km}$, the correct incorporation of GWs into general circulation models (GCMs) with coarse grids is still posing an important challenge. GWs from orographic sources are best understood and can be parameterized with reasonable accuracy (Palmer et al. 1986; McFarlane 1987; Lott and Miller 1997). Model assumptions about nonorographic waves, in contrast, are frequently unrealistic. For instance, the distribution of GW sources is sometimes specified to be uniform in space and time or to vary with only latitude and season (Garcia and Solomon 1985; Hines 1997; Manzini and McFarlane 1998; Scinocca 2003; Orr et al. 2010). Efforts to link GW sources to the meteorological situation in a GCM have been made for convective sources (e.g.,
Beres et al. 2005; Kim et al. 2013) as well as for frontal origins (e.g., Charron and Manzini 2002; Richter et al. 2010). Nevertheless, large uncertainties remain with respect to the representation of GWs in GCMs.

The aim to reduce uncertainties related to the parameterization of GWs is severely hindered by a lack of observational constraints. A single instrument or technique can only observe a certain part of the GW spectrum (Alexander et al. 2010; Geller et al. 2013). In addition, the synthesis of available data is insufficient to construct a global reference for $\mathrm{GW}$ properties. In fact, many assumptions of GW parameterizations are derived from regional cloud-resolving simulations with grid spacings sufficiently fine to capture a major fraction of the GW spectrum (e.g., Beres et al. 2004; Choi and Chun 2011). GWs in high-resolution ( $\sim 4 \mathrm{~km})$ simulations of regional mesoscale models, such as the Weather Research and Forecasting (WRF) Model, can have a high degree of realism (Grimsdell et al. 2010; Orr et al. 2015; Stephan and Alexander 2015; Stephan et al. 2016).

In the light of ever-increasing computational capabilities, the above challenges have served as a strong motivation to devise global models that can run without most or any of the traditional GW parameterizations. Liu et al. (2014) presented a mesoscale-resolving GCM, WACCM-SE, with a horizontal resolution of $\sim 0.25^{\circ}$ and a model top at $\sim 145-\mathrm{km}$ geometric height. They showed that the model produced many realistic GW features, yet the zonal drag from resolved GWs was insufficient to achieve the required forcing in the stratosphere and mesosphere. The Kanto model with a $0.56^{\circ}$ resolution in latitude and longitude and a model top at $85 \mathrm{~km}$ (Watanabe et al. 2008) achieved a mostly realistic circulation including a self-generated QBO without any GW parameterizations. This was possible because the setup of Kanto used less dissipation at small scales than would be typical for a GCM in order to minimize the damping of GWs (Geller et al. 2013). The CAM5 (Neale et al. 2010) with a latitude-longitude grid of $0.238^{\circ} \times 0.318^{\circ}$ and a model top at $2 \mathrm{hPa}$ $(\sim 40 \mathrm{~km})$ also achieved a realistic circulation, parameterizing only orographic GWs (Geller et al. 2013). In their comparison of absolute zonal-mean GWMFs between CAM5, Kanto, and coarse-grid GCMs, Geller et al. (2013) found that the magnitudes of GWMFs in Kanto were similar to those in conventional GCMs with GW parameterizations, while CAM5 GWMFs were much smaller at all latitudes despite CAM5 having a much finer resolution than Kanto. Importantly, they also found the high-resolution models to be more realistic in that their GWMFs decreased toward the poles. 
The models with nonorographic GW parameterizations did not show this behavior, which was attributed to their deficient source flux specifications. In contrast to the coarse GCMs, CAM5 and Kanto also produced a summer subtropical secondary maximum of zonalmean absolute GWMF. However, a comparison to radiosonde balloon-derived fluxes also showed that orographic GWMFs were still underresolved in both high-resolution models.

Global simulations have also been performed at convection-permitting scales. A 7-km simulation of GEOS-5, which is often referred to as the Nature Run (Gelaro et al. 2015), still employed a parameterization for orographic GWs. Holt et al. (2017) showed that this simulation generated realistic nonorographic GWs, but because of excessive dissipation the nonorographic GWMF partly needed to be parameterized. A related problem encountered at convection-permitting scales is the treatment of convection itself. The use of a convective parameterization has a strong influence on the excited GWs (Kim et al. 2007; Preusse et al. 2014). Müller et al. (2018) showed that convectively generated GWs were suppressed when a convective parameterization was turned on in their zonally symmetric aquaplanet model without rotation and no background winds. They attributed this sensitivity to a reduction of deep and strong heating at small scales. Stephan et al. (2019) confirmed this sensitivity in a comparison of GWs in two 5-km simulations with and without a convective parameterization. On the one hand, convective parameterizations have adverse effects on the realism of convective $\mathrm{GW}$ generation. On the other hand, convection remains underresolved even at grid spacings of $1 \mathrm{~km}$ (Prein et al. 2015).

While the simulations subject to this study are analyzed over the period of only one month of August, it is likely that we will soon attain the capacities required for running convection-permitting GCMs for longer periods of time. Without GW parameterizations we lose the ability to tune specific components of the atmospheric circulation system by adjusting free parameters of the different GW drag schemes (e.g., Garcia et al. 2017; Orr et al. 2010). Therefore, it is important to assess how well current convection-permitting GCMs are performing at reproducing observed features of GWMF and to understand how sensitive these features are to changes in model formulation as well as resolution. Moreover, a formal evaluation of the simulations against observational data is not a trivial task. We use and compare different analysis techniques for the calculation of GW parameters to provide guidance on how to evaluate GWs in convectionpermitting GCMs.
Section 2 introduces the simulations, observational data, and analysis methods. The results are discussed in section 3, and section 4 gives a summary and conclusions.

\section{Data and methods}

\section{a. Numerical simulations}

We analyze three-dimensional wind and temperature output from three models participating in the Dynamics of the Atmospheric General Circulation Modeled on Nonhydrostatic Domains project (DYAMOND; Stevens et al. 2019, manuscript submitted to Prog. Earth Planet. Sci.). The models are the Icosahedral Nonhydrostatic model (ICON; Zängl et al. 2015), the Nonhydrostatic Icosahedral Atmospheric Model (NICAM; Satoh et al. 2008, 2014), and the Integrated Forecasting System (IFS; Wedi 2014; Malardel et al. 2016). We chose these three models from the nine models that participated in DYAMOND because their model tops are sufficiently high to allow for the analysis of resolved stratospheric GWs without a strong influence of the damping layer at the model top. The DYAMOND database contains simulations at two different resolutions for each of the chosen models.

ICON and NICAM solve the fully compressible Navier-Stokes equations on icosahedral grids, while IFS is a hydrostatic model discretized on a cubic octahedral grid. ICON was run at 2.5 - and 5-km horizontal resolutions and with 90 levels in the vertical up to the model top at $75 \mathrm{~km}$, NICAM at 3.5- and 7-km horizontal resolution with 78 vertical levels extending up to $50 \mathrm{~km}$, and IFS at 4and 9-km horizontal resolutions with 137 vertical levels and a model top at $80 \mathrm{~km}$. Between 20 - and $40-\mathrm{km}$ heights there are 16 vertical levels in ICON, 15 in NICAM, and 30 in IFS. We will refer to the simulations with the model name and horizontal resolution (e.g., NICAM-3.5).

All models use a sponge layer to prevent the reflection of waves from the model top. In NICAM second-order 2D Laplacian damping is applied at all levels for numerical stability, and enhanced in the sponge layer, which starts at $20 \mathrm{~km}$. In addition, first-order 2D Laplacian damping is active in the sponge layer and applied to all dynamical variables including horizontal and vertical wind. In ICON Klemp-type implicit Rayleigh damping (Klemp et al. 2008) of vertical winds starts at $44 \mathrm{~km}$. The stratospheric sponge of IFS uses wavenumber-dependent fourthorder diffusion and starts at $10 \mathrm{hPa}$. IFS includes two extra sponge layers: a mesospheric sponge that acts on the divergence from $1 \mathrm{hPa}$ to the model top and a sponge at the three top levels that acts on vorticity. ICON-5, ICON2.5, NICAM-7, and NICAM-3.5 do not use any parameterization for convection, while IFS-9 parameterizes 
shallow, midlevel, and deep convection (Bechtold et al. 2008), and IFS-4 parameterizes shallow convection. All simulations were initialized at 0000 UTC 1 August 2016 from an operational analysis of the atmospheric state, which was produced by the European Centre for Medium-Range Weather Forecasts (ECMWF), and integrated forward for 40 days until 0000 UTC 10 September 2016. The simulations were forced at the lower boundary with daily sea surface temperatures also taken from the analysis of ECMWF. ICON and NICAM do not use any type of GW drag parameterizations. The physics parameterizations in IFS are those of the operational setup and include nonorographic (Scinocca 2003) and orographic (Lott and Miller 1997) GW drag parameterizations.

The atmospheric state variables were saved every three hours, while 2D variables like surface properties were saved every $15 \mathrm{~min}$ for ICON and NICAM and every hour for IFS. To derive the stratospheric GWMF we interpolate simulated three-dimensional wind and temperatures between 20 - and $40-\mathrm{km}$ altitudes vertically and horizontally to a common grid. This grid has a constant $500-\mathrm{m}$ vertical spacing and a horizontal resolution of $0.2^{\circ} \times 0.2^{\circ}$ latitude-longitude. This horizontal resolution is chosen to be close to the typical effective resolution of the simulations considered here, and it is sufficient for our wave analysis, which focuses on horizontal wavelengths of $O(100-1000) \mathrm{km}$. All computations use instantaneous output at 0600, 1200, 1800, and 2400 UTC between 2 and 31 August. We exclude the first 2 days of the simulations to allow for sufficient spinup time and to avoid artifacts from potential initialization shocks.

\section{b. Observational data}

To compare the occurrence frequencies of simulated hourly precipitation rates at $0^{\circ}-40^{\circ} \mathrm{N}$ (interpolated to $0.1^{\circ} \times 0.1^{\circ}$ ) to observations, we use 30 -min $0.1^{\circ} \times 0.1^{\circ}$ precipitation data for August 2016 from the Tropical Rainfall Measuring Mission (TRMM; Huffman 2017). Topographic elevation for identifying orographic wave sources are taken from the ETOPO1 1-arc-min global relief model (Amante and Eakins 2009).

GWMF derived from simulations is compared to global data of absolute GWMF at 30-km altitude from the Gravity Wave Climatology Based on Infrared Limb Emissions Observed by Satellite (GRACILE) climatology (Ern et al. 2018). GRACILE is derived from measurements by the infrared limb sounders High Resolution Dynamics Limb Sounder (HIRDLS) and Sounding of the Atmosphere using Broadband Emission Radiometry (SABER). The vertical coverage for horizontal distributions of pseudomomentum flux is
$30-90 \mathrm{~km}$ for SABER and $30-50 \mathrm{~km}$ for HIRDLS. The limb measurement technique is able to detect GWs with horizontal wavelengths $\lambda_{h} \geqslant 100-200 \mathrm{~km}$ and vertical wavelengths $\lambda_{z} \geq 3 \mathrm{~km}$. Both satellite instruments provide only a single track of measurements along their flight paths. GW amplitudes and $\lambda_{z}$ are estimated from retrieved vertical profiles of temperatures. For each vertical profile the analysis focuses on only the strongest component. Consecutive altitude profiles are used to determine vertical phase shifts of observed temperature structures to estimate $\lambda_{h}$ and the absolute GWMF (Ern et al. 2004, 2011). The data are distributed into overlapping longitude-latitude boxes and averaged to obtain global distributions. The bins measure $15^{\circ} \times 5^{\circ}$ for HIRDLS and $30^{\circ} \times 20^{\circ}$ for SABER, as fewer data can be retrieved from SABER measurements (Ern et al. 2018). Ern et al. (2004) argued that estimates of absolute GWMF values derived from HIRDLS and SABER should be considered lower bounds of the true GWMF because of attenuation due to instrument sensitivity and because computations use the along-track estimate of $\lambda_{h}$ instead of the true horizontal wavelength. Details of the measurement sensitivities are described in Ern et al. (2018).

As another measure of stratospheric GW activity we compare simulated temperature variances at $20-40 \mathrm{~km}$ to the Atmospheric Infrared Sounder (AIRS) climatology of radiance measurements for August 2016 (Hoffmann et al. 2013, 2014). AIRS operates on board NASA's Aqua satellite in a nearly polar orbit with equatorial crossings at 0130 and 1330 local time. Every $18 \mathrm{~km}$ along its track, the infrared nadir sounder AIRS performs across-track scans that cover $1780-\mathrm{km}$ ground distance. One scan consists of 90 footprints that vary in size between $14 \mathrm{~km} \times 14 \mathrm{~km}$ at nadir and $21 \mathrm{~km} \times$ $42 \mathrm{~km}$ at the scan edges. GW signals are isolated by removing a fourth-order polynomial function from each scan that is obtained from a fit to mean brightness temperatures from 42 AIRS channels in the $4.3-\mu \mathrm{m}$ spectral region. In this way, GWs with $\lambda_{h} \geq 15-20 \mathrm{~km}$ and $\lambda_{h} \geq 30 \mathrm{~km}$ can be observed. The weighting functions and response curves that indicate the sensitivity of the measurements as a function of altitude are shown in Hoffmann and Alexander (2010) and Hoffmann et al. (2013, 2014). A climatological dataset containing brightness temperature variances on a $4^{\circ} \times$ $2^{\circ}$ longitude-latitude grid for the years 2002-18 has been made available to the community (https://doi.org/ 10.17616/R34J42).

\section{c. Resolved gravity waves in simulations}

The vertical flux of horizontal pseudomomentum associated with GWs of intrinsic frequency $\hat{\omega}$ is given by 


$$
\left(F_{x}, F_{y}\right)=\rho_{0}\left(1-\frac{f^{2}}{\hat{\omega}^{2}}\right)\left(\overline{u^{\prime} w^{\prime}}, \overline{v^{\prime} w^{\prime}}\right)
$$

where $\rho_{0}$ is the background density, $f$ the Coriolis parameter, $\left(u^{\prime}, v^{\prime}, w^{\prime}\right)$ the vector of three-dimensional wind velocity perturbations, and overlines denote averages over at least one wavelength. An exact computation of the resolved GWMF would require a spectral analysis in space and time of the wind field to determine the covariance of zonal and meridional wind variations, respectively, with variations of the vertical wind component. Typically, as is also the case here, this is not feasible for GCM simulations, as it would require model output at much higher frequencies [O$O(10) \mathrm{min}]$. The DYAMOND output of three-dimensional fields is 3 hourly. Therefore, we compute the resolved GWMF with two methods that use regridded data at single time steps. One method, S3D, is based on three-dimensional sinusoidal fits to subsets of the perturbation temperature field. The other method, which we will refer to as WTQ, is an approximation based on wind and temperature quadratics.

\section{1) S3D METHOD}

The small-volume few-wave decomposition technique S3D (Lehmann et al. 2012) renders local threedimensional wave vectors and GWMF amplitudes. Thus, the technique provides information on GW parameters as a function of physical space, as opposed to, for instance, Fourier analysis. S3D yields information on the wave that explains the largest fraction of the variance in the temperature perturbation field inside a given three-dimensional spatial subset of data. The analysis is based on the following steps:

- Filtering data-We obtain temperature perturbations from the regridded data by removing zonal waves of wavenumbers up to 12 . Sensitivity tests showed that cutoff wavenumbers of 6 or 18 do not significantly affect the results. The background removal is required to eliminate planetary waves and large-scale temperature gradients. Close to the poles the filtering method may remove GWs as well, but we do not discuss GWs near the poles. Our spectral definition of the background, as opposed to a dynamical definition based on, for example, a separation of geostrophically balanced from unbalanced flow, is well justified in the stratosphere. Unlike in the troposphere, the spectral gap between geostrophic motion and wave motion is large in the stratosphere, as can be seen, for instance, from Figs. 2e and 2f in Callies et al. (2016) and was also shown in Koshyk and Hamilton (2001).

- Subsetting data-Several choices need to be made when applying S3D to arrive at a fair comparison to the GRACILE climatology. S3D is applied to the resulting temperature perturbations after their array is divided into small cubes that measure $15 \mathrm{~km}$ in the vertical direction, $140 \mathrm{~km}$ in the meridional direction and, on average, $140 \mathrm{~km}$ in the zonal direction. A cube spans nine grid points in the zonal direction and seven grid points in the meridional direction with its center placed at $30-\mathrm{km}$ height. We cover the globe with $300 \times 150$ cubes in the zonal and meridional direction, respectively, such that they overlap by onethird of their width. S3D results are collected on a $1.2^{\circ} \times 1.2^{\circ}$ longitude-latitude grid, according to the number of cubes. The cube dimensions are based on results from previous studies (Lehmann et al. 2012; Krisch et al. 2017; Stephan et al. 2019) to focus the analysis on wavelengths that allow for a fair comparison to the GRACILE climatology.

- Fitting waves-A separate sinusoidal fit is applied to temperatures perturbations inside each cube to extract the wave explaining the largest fraction of the variance. This has several important implications. The vertical and horizontal wavelengths are not bound by the cube dimensions, as would be the case for Fourier spectra. In theory, the minimum detectable $\lambda_{h}$ is $\sim 40 \mathrm{~km}$, corresponding to about twice the grid spacing of the regridded data. However, the fit assumes a constant wave vector over the cube, which is more likely to hold for $\lambda_{h} \sim O$ (cube size) or larger. The wave vector would change substantially across the cube for, for example, a convective wave source (forming arc-like wave fronts) or in case of strong wave refraction. Thus, most fitted wave vectors exceed the cube dimensions. Lehmann et al. (2012) showed for the most unfavorable conditions (i.e., spatially homogeneous, full spectra) that S3D can retrieve spectral distributions with horizontal wavelengths up to 11 times the cube size.

Through sinusoidal fits the leading wave inside each cube is fully characterized in terms of its amplitude $\hat{T}$ and its zonal, meridional, and vertical wavenumbers $(k, l, m)$. From these parameters GWMF is computed according to linear wave theory as (cf. Ern et al. 2004)

$$
\left(F_{x}, F_{y}\right)=\frac{1}{2} \rho_{0} \frac{(k, l)}{m}\left(\frac{g}{N}\right)^{2}\left(\frac{\hat{T}}{T_{0}}\right)^{2},
$$

where $g$ denotes the gravitational acceleration and $N$ is the buoyancy frequency. Assuming upward wave propagation fixes the ambiguity in the horizontal propagation direction of a wave.

- Rejecting long wavelengths-The aforementioned upper limit on a detectable wavelength $\lambda_{\zeta}^{*}$ in the 
direction $\zeta$ would imply $\lambda_{\zeta}^{*} \sim 10 \times O\left(\Delta_{\zeta}\right)$ for a cube size $\Delta_{\zeta}$ (Lehmann et al. 2012). Of course, the actual limit depends on the physical problem that is addressed and the geometry of the cubes. For our estimation of $\lambda_{\zeta}^{*}$ we discern between the vertical $(\zeta=z)$ and horizontal directions $(\zeta=h)$. Rejected waves $\left(\lambda_{\zeta}>\lambda_{\zeta}^{*}\right)$ are excluded from the calculation of maps or zonal means.

As GWMF is proportional to $\lambda_{z}$, but inversely proportional to $\lambda_{h}$, it is of critical importance to avoid unrealistically large $\lambda_{z}$. A sinusoidal fit is robust as long as a little less than $0.5 \lambda_{\zeta}$ is contained inside a cube for a given dimension. Accordingly, our vertical cube size $\Delta_{z}$ is chosen such that $\lambda_{z} \geq 2.5 \Delta_{z}$ for the vast majority of the waves (as will be shown later in Fig. 3). Rare outliers, which mark unreliable fits, are rejected when $\lambda_{z}>2.5 \Delta_{z}$.

For a wave with horizontal wavenumber $\kappa$, vertical wavenumber $m$, and propagation in the $(x, z)$ plane, the wave's phase can be expressed as $\phi=$ $\kappa x+m z+\phi_{0}$. Thus, for $z$ fixed, $\phi_{1}-\phi_{2}=\kappa\left(x_{1}-x_{1}\right)$, or more generally $\kappa=2 \pi / \lambda_{h}=\Delta \phi / \Delta_{h}$. Then, under the conservative assumption that the sampling error in a spatial direction is the full grid distance in that direction (denoted by $\delta_{h}$ and $\delta_{z}$, respectively), error propagation yields

$$
\delta \kappa=\frac{1}{\sqrt{N_{h}}} \sqrt{\left[\frac{\delta(\Delta \phi)}{\Delta_{h}}\right]^{2}+\left(\frac{\kappa \delta_{h}}{\Delta_{h}}\right)^{2}},
$$

where $N_{h}$ is the number of points in the horizontal direction. The error for $\Delta \phi$ is obtained from the vertical direction. As above, but now for $x$ fixed, $m=$ $2 \pi / \lambda_{z}=\Delta \phi / \Delta_{z}$ and therefore $\delta(\Delta \phi)={\sqrt{N_{z}}}^{-1} m \delta_{z}$. Evidently, the second term under the square root in (3) is very small for $\lambda_{h}>\Delta_{h}$ and we neglect it. Finally, by requiring that $\kappa$ be an order of magnitude greater than its error for a well-defined fit (i.e., $\kappa^{*}=10 \delta \kappa$ ), we obtain

$$
\lambda_{h}^{*}=\sqrt{N_{h}} \sqrt{N_{z}} \frac{\Delta_{h} \lambda_{z}}{10 \delta_{z}}
$$

For a conservative estimate of $\lambda_{z} \sim 5 \mathrm{~km}$ (see distributions in Fig. 3 below), this limits $\lambda_{h}^{*}$ to roughly $2500 \mathrm{~km}$. This value is of the same size as the longest wavelengths retained after the background removal and is also generally consistent with the tests from Lehmann et al. (2012).

\section{2) WTQ METHOD}

Assuming the presence of only a single monochromatic wave, the associated GWMF can be calculated based on linear wave theory using the polarization relations for GW as (cf. Geller et al. 2013)

$F_{x}^{2}+F_{y}^{2}=\rho_{0}^{2}\left(1-\frac{f^{2}}{\hat{\omega}^{2}}\right)^{2} w^{\prime 2}\left(u^{\prime 2}+v^{\prime 2}\right)\left[1+\frac{f^{2}}{\hat{\omega}^{2}}\right]^{-1}$,

where $\left(u^{\prime}, v^{\prime}, w^{\prime}\right)$ are defined as deviations from a background computed with the same spectral detrending as for S3D. The term in square brackets corrects for the wind component perpendicular to the wave propagation direction, which does not contribute to the pseudomomentum flux and has an amplitude of $f^{2} / \hat{\omega}^{2}$ times the amplitude of the parallel wind component. Furthermore, the intrinsic frequency $\hat{\omega}$ is also calculated from the fluctuation quantities according to

$$
\frac{f^{2}}{\hat{\omega}^{2}}=\left(\frac{f g}{w^{\prime} N^{2}}\right)^{2}\left(\frac{T^{\prime}}{T_{0}}\right)^{2}
$$

Note that these two equations do not include any information about the phase relationships between the variables. While they are exact for monochromatic waves, they are an approximation for a superposition of waves. In the latter case, shorter wavelengths are associated with larger $w^{\prime}$ and longer wavelengths with larger $u^{\prime}, v^{\prime}$, and $T^{\prime}$. Thus, in general, the equations mix the contributions of different waves. To reduce these nonphysical cross terms, which grow with the width of the GW spectrum included, we first remove variability at scales smaller than the (latitude dependent) S3D horizontal cube size using a boxcar-average low-pass filter. We evaluate the equations at each single point, then average over the whole considered time period.

The low-pass filtering subjects WTQ to a similar spectrum as seen by $\mathrm{S} 3 \mathrm{D}$, and it allows to fairly compare the simulations, as they differ substantially in the damping of short $\lambda_{h}$ (Fig. 1). While short wavelengths are important, they are not the focus of this study. Instead, we assess that part of the spectrum that is well resolved by all simulations and can be compared to global observations.

\section{Results}

We compare the set of six numerical simulations to determine 1) differences between models and 2) systematic effects of changing the resolution between simulations of the same model. In doing so we will also 3) compare S3D and WTQ results.

\section{a. Temperature power spectra}

To facilitate the interpretation and comparison of the results derived from S3D and WTQ, we first examine 
(a) Fourier power spectrum of $T(x)$ at $30 \mathrm{~km}$

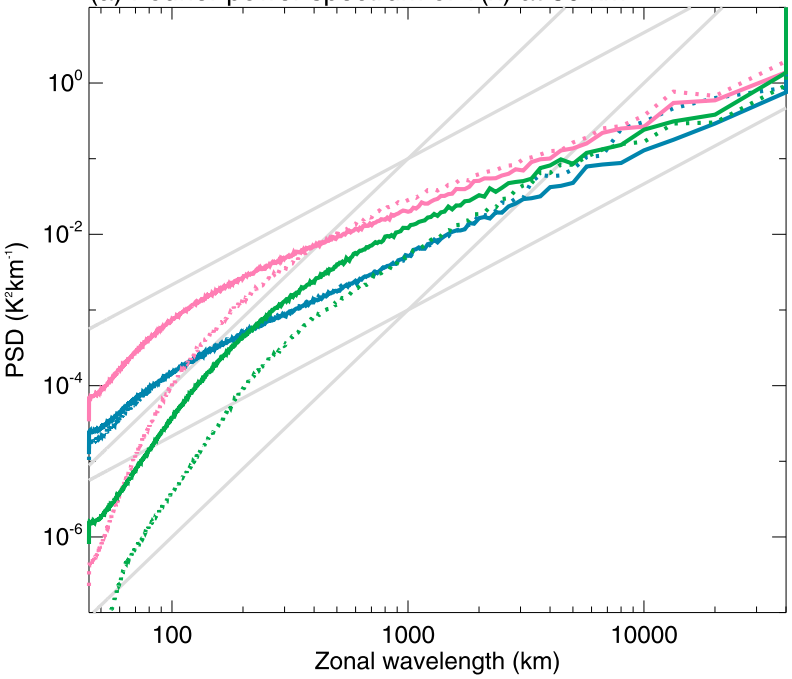

(b) S-transform power spectrum of $\mathrm{T}(\mathrm{z})$ at $\mathrm{z}=30 \mathrm{~km}$

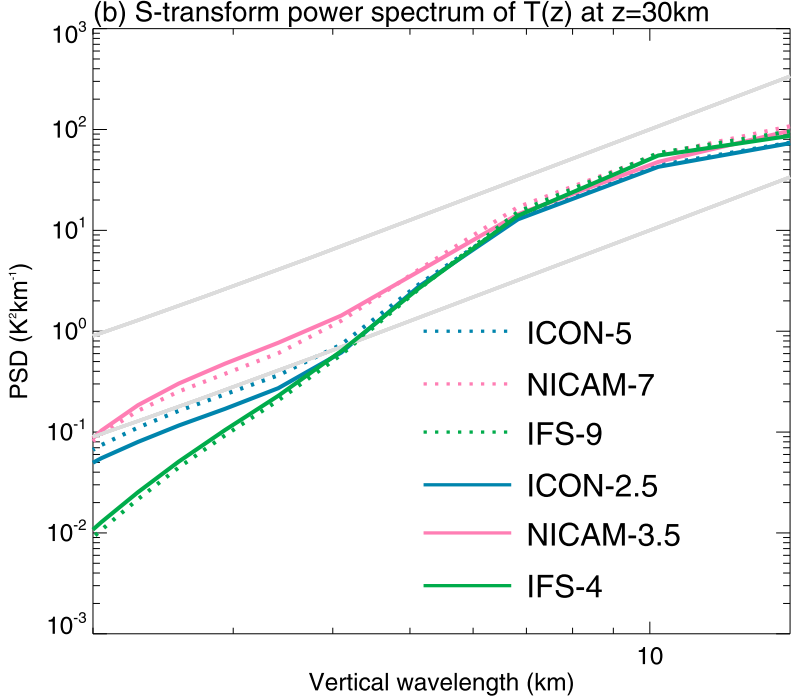

FIG. 1. Power spectral densities of temperature perturbations at $30 \mathrm{~km}$ as functions of (a) zonal and (b) vertical wavelengths. The curves in (a) are Fourier spectra computed from temperature perturbations varying with longitude $T(x)$, averaged over the latitudes $5^{\circ} \mathrm{S}-5^{\circ} \mathrm{N}$. The curves in (b) are computed from the $30-\mathrm{km}$ amplitude of S-transformations (Stockwell et al. 1996) applied to temperature perturbations $T(z)$ varying with height between 20 and $40 \mathrm{~km}$, averaged over all grid points in $5^{\circ} \mathrm{S}-5^{\circ} \mathrm{N}$. Gray lines in (a) show slopes of $k^{-5 / 3}$ (shallow) and $k^{-3}$ (steep), and gray lines in (b) show slopes of $\mathrm{m}^{-3}$.

stratospheric zonal and vertical power spectra of temperature perturbations (Fig. 1). NICAM-3.5 contains the most power across all $\lambda_{h}$, whereas NICAM-7 is damped at $\lambda_{h} \lesssim 500 \mathrm{~km}$. In IFS, particularly in IFS-9, the effects of damping are even stronger. The spectra of IFS-9 and IFS-4 start to diverge at $\lambda_{h} \approx 4000 \mathrm{~km}$. At $\lambda_{h}=100 \mathrm{~km}$ power in IFS is orders of magnitude smaller compared to ICON and NICAM. Only the spectra of
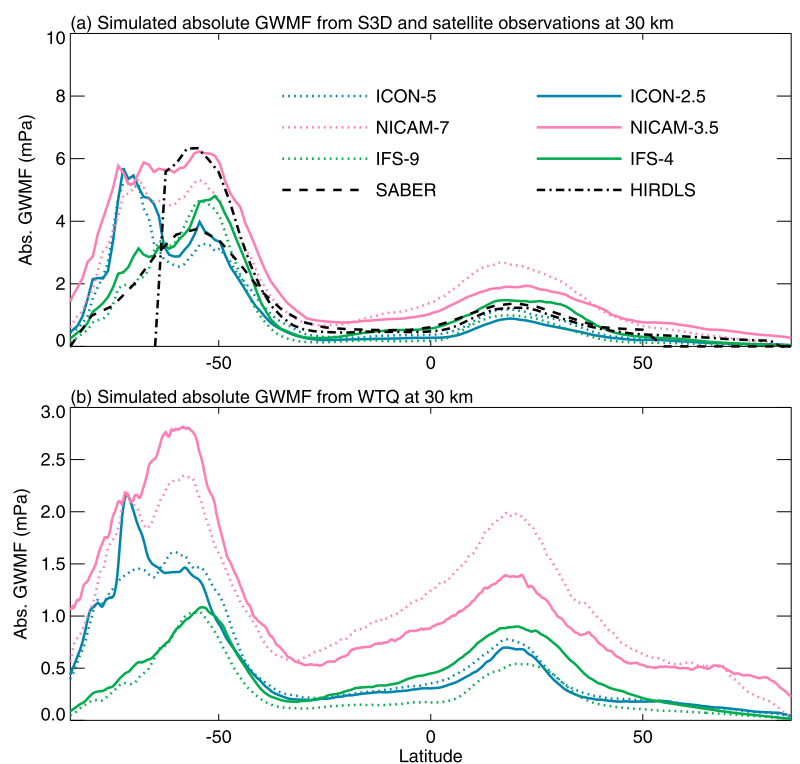

FIG. 2. (a) August-mean zonal-mean absolute GWMF at $30 \mathrm{~km}$ for all simulations and observed by HIRDLS and SABER. Simulated GWMF is computed by applying (a) S3D and (b) WTQ. Differences between the profiles from HIRDLS and SABER south of $40^{\circ} \mathrm{S}$ mainly result from HIRDLS's ability to sample shorter horizontal wavelengths at $40^{\circ}-63^{\circ} \mathrm{S}$ due to its favorable observational geometry at these latitudes. This captures accordingly a larger part of the GWMF spectrum. Latitudes south of $63^{\circ} \mathrm{S}$ are only covered by SABER.

ICON show hardly any differences between the 2.5 - and $5-\mathrm{km}$ setups of the model at short $\lambda_{h}$. There is only slightly more power in ICON-2.5 at $\lambda_{h} \lesssim 60 \mathrm{~km}$. In contrast to the horizontal power spectra, the simulations differ little in terms of their vertical power spectra (Fig. 1b). At $\lambda_{z} \gtrsim 7 \mathrm{~km}$ the curves of all six simulations lie on top of each other. The small differences at shorter $\lambda_{z}$ are not expected to influence the S3D results presented here because the majority of S3D-fitted waves have $\lambda_{z}>5 \mathrm{~km}$, as is shown later. Yet waves of short $\lambda_{z}$ may contribute to WTQ-derived GWMFs. It is possible that differences in the spectra are partly due to different vertical grid spacings of the models.

\section{b. Zonal-mean absolute and net GWMF}

Figure 2a compares the S3D-derived zonal-mean absolute GWMF at $30 \mathrm{~km}$ between ICON, NICAM, IFS, HIRDLS, and SABER. The relative distributions agree very well between all simulations and observations. All meridional profiles show a strong peak at winter mid- to high latitudes and a second maximum in the Northern Hemisphere subtropics, with decreasing absolute GWMF toward the poles. Absolute values match within a factor of $2-3$. The summer hemisphere peak has been attributed before to convective GW 
(a) $0-30 \operatorname{deg} N$

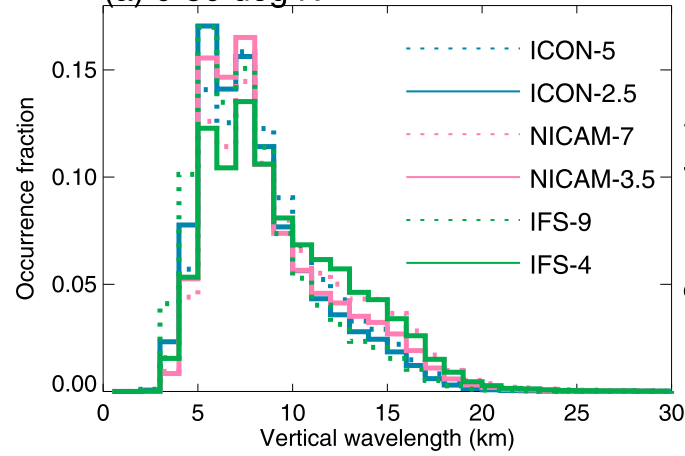

(c) $35-65$ deg $\mathrm{S}$

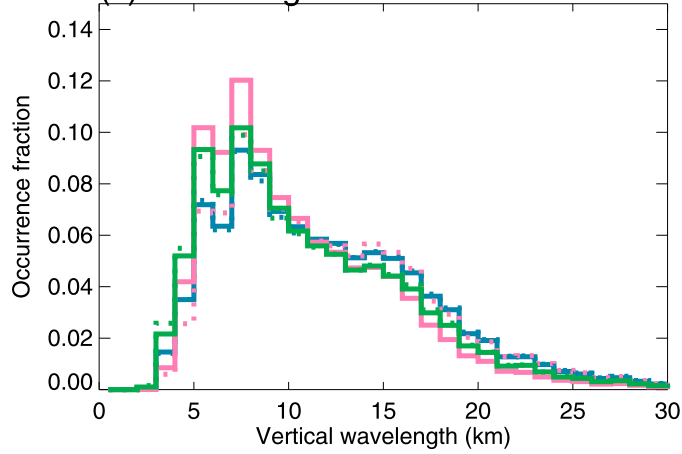

(b) $0-30 \operatorname{deg} \mathrm{N}$

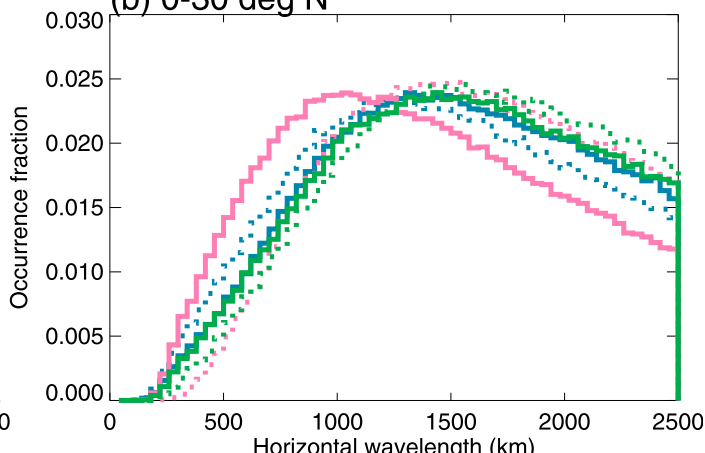

(d) $35-65 \operatorname{deg} \mathrm{S}$

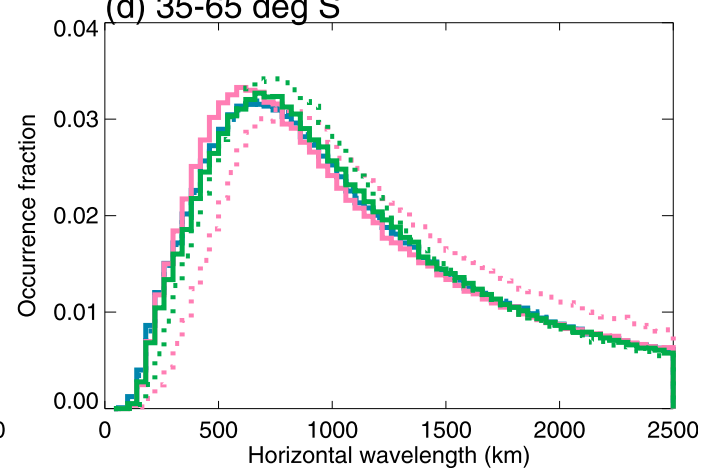

FIG. 3. Fractional occurrence of (a), (c) vertical and (b), (d) horizontal wavelengths from S3D for (a),(b) $0^{\circ}-30^{\circ} \mathrm{N}$ and (c), (d) $35^{\circ}-65^{\circ} \mathrm{S}$.

sources (McLandress et al. 2000; Preusse et al. 2001; Hoffmann and Alexander 2010; Choi et al. 2012), while the peak at middle to high southern latitudes has been attributed to orography (Eckermann and Preusse 1999; McLandress et al. 2000) and enhanced GW activity in the polar vortex (Sato and Yoshiki 2008; Fritts et al. 2016).

S3D-derived GWMFs of ICON and IFS are generally smaller or equal to observed, whereas those of NICAM are generally greater than observed. The WTQ-derived zonal-mean absolute GWMFs are qualitatively similar to the S3D results (Fig. 2b). This is not self-evident given that the two methods are very different in that S3D is based on only the temperature field and focuses on the dominant wave, whereas WTQ is based on temperatures and three-dimensional winds.

Across the models, neither S3D nor WTQ show evidence for a systematic effect of resolution. For simulations of the same model, the effects of changes in resolution on S3D and WTQ GWMFs are different for the two dominant regions of GWMF.

Across the six simulations, relative differences are smaller in S3D than in WTQ. By construction, the algorithm produces similar statistics in terms of fitted $\lambda_{z}$ and $\lambda_{h}$. Indeed, Fig. 3 shows that at $0^{\circ}-30^{\circ} \mathrm{N} \lambda_{z}$ is predominantly $5-8 \mathrm{~km}$ and at $35^{\circ}-65^{\circ} \mathrm{S}$ it is $8-15 \mathrm{~km}$, with very good agreement between the simulations. Satellites also measure slightly longer average $\lambda_{z}$ at $35^{\circ}-$ $65^{\circ} \mathrm{S}$ (SABER: $11.3 \mathrm{~km}$; HIRDLS: $11.5 \mathrm{~km}$ ) than at $0^{\circ}-$ $30^{\circ} \mathrm{N}$ (SABER: $10.0 \mathrm{~km}$; HIRDLS: $9.4 \mathrm{~km}$ ). Of course, a prerequisite for the good agreement between simulations is that waves of the dominant $\lambda_{z}$ range are present in all simulations. We know from Fig. 1 that this is equally true for all simulations considered here.

The most noticeable feature in the $\lambda_{h}$ distributions is a shift to shorter $\lambda_{h}$ with finer horizontal resolution in NICAM, which is seen both at $0^{\circ}-30^{\circ} \mathrm{N}$ and at $35^{\circ}-65^{\circ} \mathrm{S}$. This shift is consistent with the stronger damping at short horizontal scales in NICAM-7. The good agreement between the simulations in Fig. 3 supports that the smaller spread of GWMF magnitudes in S3D compared to WTQ can partly be attributed to focusing the analysis more strongly on the larger-amplitude waves in a considered region and thereby on a certain part of the GW spectrum.

S3D also gives the net GWMF. Theoretically, a different absolute GWMF could be associated with identical net GWMF when eastward and westward, or northward and southward, respectively, net GWMFs partly compensate. Figure 4 shows the S3D-derived zonal-mean zonal and meridional net GWMF of all simulations. As in the case of absolute GWMF, 

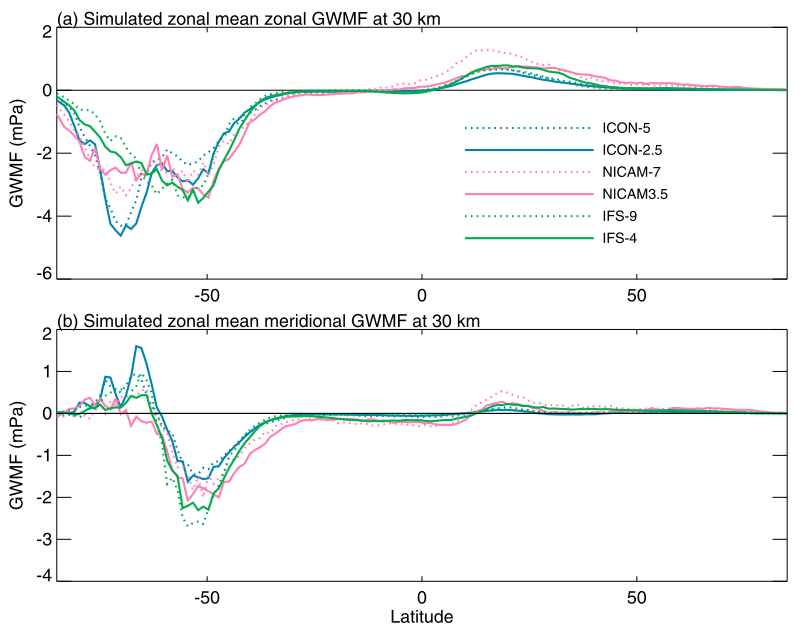

FIG. 4. August-mean zonal-mean net (a) zonal and (b) meridional GWMFs at $30 \mathrm{~km}$ derived from S3D for all simulations.

the net fluxes agree within a factor of 2 . The net zonal GWMF is directed opposite to the prevailing stratospheric zonal wind (Ern et al. 2017). In the Southern Hemisphere GWs converge near the polar vortex (Sato et al. 2009).

Figure 2, particularly the WTQ results in Fig. 2b, shows that intramodel differences exist even at scales that substantially exceed the grid resolution of the simulations. While small discrepancies may also result from different synoptic evolutions, resolutiondependent GW sources as well as GW propagation characteristics are likely to contribute to systematic differences between simulations of the same model. The next subsections examine different key source regions in more detail.

\section{c. Horizontal distribution of GWMF}

To investigate which regions contributes the most to the zonal-mean GWMF, we next examine global maps of S3D- and WTQ-derived absolute GWMF for all simulations. The climatological August GWMF observed by SABER and HIRDLS is shown with the S3D results (Fig. 5). Qualitatively, all simulations produce a detailed match of the observed global GWMF pattern in S3D (Fig. 5). The agreement between S3D and WTQ is again very good, with weaker amplitudes in WTQ (Fig. 6), as expected from Fig. 2. For instance, all simulations produce the three peaks of GWMF over the Caribbean Sea, northeast Africa, and southern Asia, which are predominantly associated with convection. In this latitude band, models with convective GW source schemes tend to have the largest GWMFs over the intertropical convergence zone, while both observations and simulations show GWMF maxima over the continents in the summertime subtropics (Fig. 5). In addition, observations show a relationship between warm sea surface temperatures and middle-atmosphere GWs (Jia et al. 2014). The simulated enhanced GWMF along the eastern continental coasts above warm ocean currents, and the reduced GWMF along western continental coasts above colder SSTs, indicate that the sources of convectively generated GWs are well captured by all simulations.

Maps of the zonal and meridional GWMF at $30 \mathrm{~km}$ (not shown) reveal that the absolute GWMF peaks in the Northern Hemisphere are mostly associated with large positive values of zonal GWMF; meridional GWMF magnitudes are everywhere close to zero except for the pronounced dipole in the Southern Hemisphere (Fig. 4b). The negative peak of this dipole is a consequence of strong negative meridional GWMF at all longitudes, whereas the positive peak of the dipole mainly results from the Antarctic Peninsula and the mountain ridge in Victoria Land. These two Antarctic hotspots are also clearly visible in Fig. 5. The zonal GWMF over the Southern Hemisphere midlatitudes is slightly negative or close to zero without any notable spatial structures.

To gain a deeper understanding of the $30-\mathrm{km} \mathrm{GWMF}$ distributions it is useful to examine lower levels as well. In the following we will first discuss convective sources in the Northern Hemisphere, then orographic and jet sources in the Southern Hemisphere.

\section{1) CONVECTIVE SOURCES}

The generation of GWs by convection is affected by many parameters, including lower-level wind shear, the width and depth of convective cells (Beres et al. 2004, 2005), and resonance between wave modes and latent heating (Kang et al. 2017). At the model resolutions considered here, parameterizations for deep convection are turned off (with the exception of IFS-9), but deep convection is still underresolved. Details of the average vertical heating distribution that could result, for instance, from the use of different microphysics schemes, are not expected to have large effects on the resulting GWs (Stephan and Alexander 2014). Therefore, we assume that the occurrence frequencies of hourly $0.1^{\circ} \times 0.1^{\circ}$ precipitation rates at $0^{\circ}-40^{\circ} \mathrm{N}$ can provide a reasonable first-order approximation for the strength of convective GW sources (Fig. 7).

Precipitation strengths of $40-100 \mathrm{~mm} \mathrm{~h}^{-1}$ are most frequent in NICAM-7 and in NICAM-3.5, which is consistent with the greater S3D and WTQ GWMF of NICAM. In fact, Northern Hemisphere S3D- and WTQ-derived GWMFs in Fig. 2 approximately scale with the occurrence frequencies of strong precipitation in Fig. 7 for all simulations. Thus, the convective 


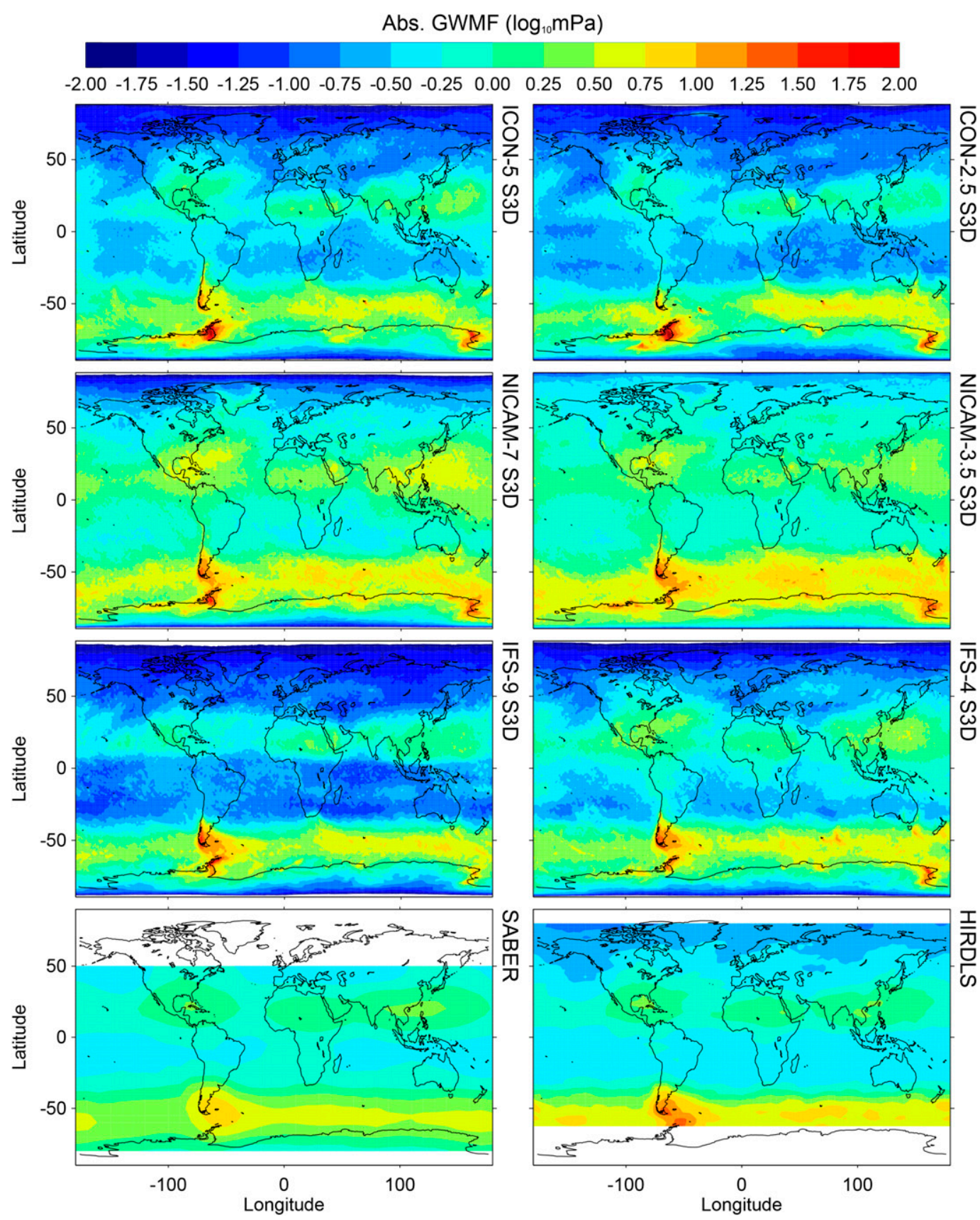

FIG. 5. August-mean absolute GWMF at $30 \mathrm{~km}$ for all simulations derived from S3D and observed by HIRDLS and SABER.

source strength may help explain the differences between simulations of the same model as well as between models.

Aside from convective source strength, differences at $30 \mathrm{~km}$ could also be linked to changes in GW propagation or filtering, as a result of different background wind profiles. We expect induced intermodel differences to be small, as the simulations are relatively short and initialized from the same atmospheric state. Figure 8 shows that the global-mean magnitude of absolute GWMF decreases at similar rates in all simulations, which supports the concept that differences at $30 \mathrm{~km}$ are connected to tropospheric sources.

Interestingly, precipitation strengths in NICAM and ICON reduce with finer horizontal resolution, whereas in IFS they increase with finer horizontal resolution. 


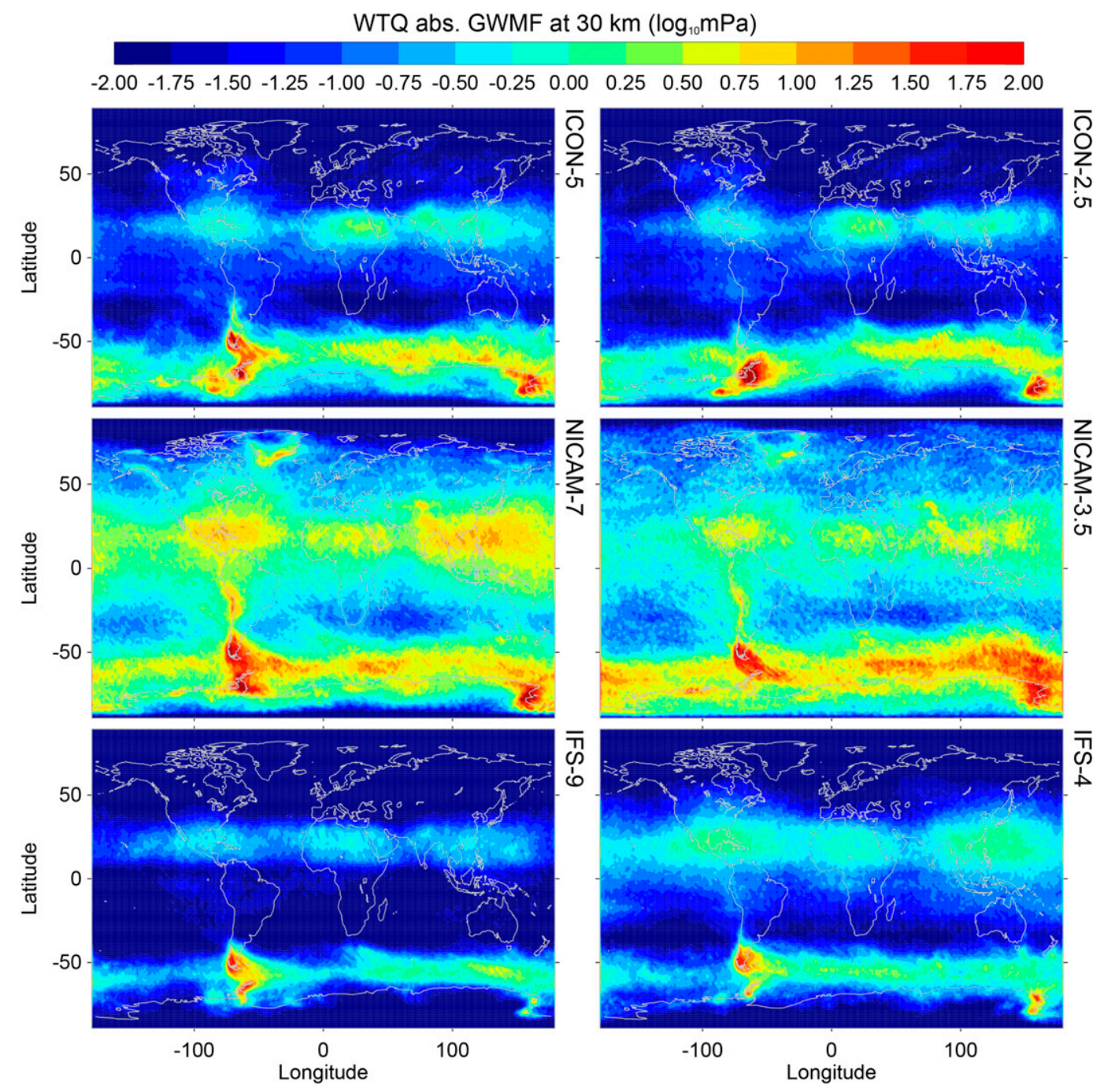

FIG. 6. August-mean absolute GWMF at $30 \mathrm{~km}$ for all simulations derived from WTQ.

The most probable explanation for this obverse behavior is that IFS switches from parameterizing shallow, midlevel, and deep convection in IFS-9 to parameterizing only shallow convection in IFS-4. Additionally, different dynamical cores, hydrostatic in IFS and nonhydrostatic in NICAM and ICON, may contribute to differing precipitation statistics. Jeevanjee (2017) showed that hydrostatic models can overestimate convective vertical velocities by a factor of 2-3 in convection-resolving regimes.

In the Northern Hemisphere absolute GWMF at $14 \mathrm{~km}$ (Fig. 9) is more widely spread than at $30 \mathrm{~km}$ (Fig. 6). However, these maps at $14 \mathrm{~km}$ should be interpreted with great caution; they are likely contaminated by unphysical contributions from deep convection inside the troposphere, as well as by small-scale synoptic waves. Nevertheless, they provide valuable information.
There is a close link between the Northern Hemisphere absolute GWMF peaks at $14 \mathrm{~km}$ and precipitation variability (Fig. 11). The 14-km GWMF signature from the more widespread and stronger convection over Southeast Asia and the western North Pacific in NICAM is still seen at $30 \mathrm{~km}$, and the same holds for the western North Atlantic. Hence, the correspondence between precipitation and 30-km GWMF does not only hold for zonal means but regionally.

\section{2) OROGRAPHIC AND JET SOURCES}

In the Southern Hemisphere, peak GWMFs are associated with orographic waves from Antarctica and the Andes Mountains (Fig. 5). In addition, the Southern Hemisphere storm tracks and jets are important GW sources. All simulations show strong absolute $30-\mathrm{km}$ GWMF south of $50^{\circ} \mathrm{S}$, in a latitude band that is nearly 


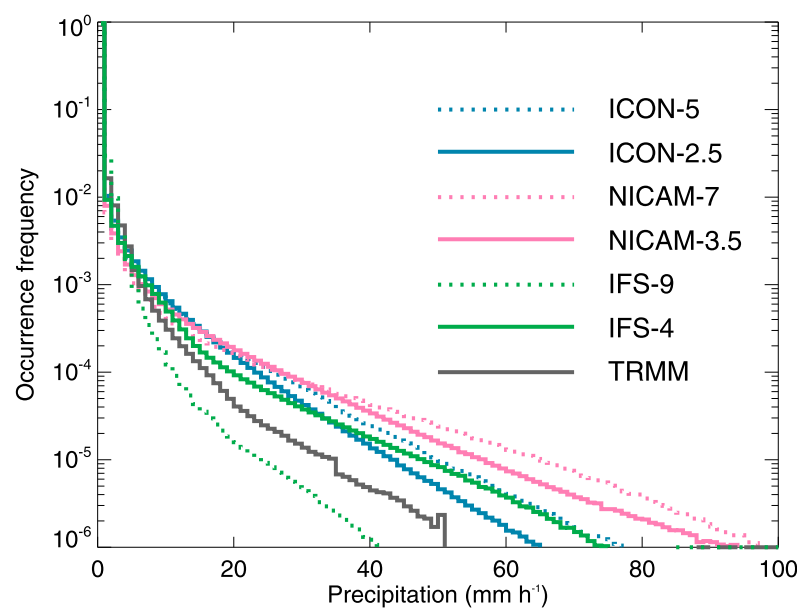

FIG. 7. Occurrence frequency of hourly $0.1^{\circ} \times 0.1^{\circ}$ precipitation rates at $0^{\circ}-40^{\circ} \mathrm{N}$ for all simulations and TRMM for August 2016.

devoid of GWMF at $14 \mathrm{~km}$ (with the exception of a few local mountain wave hotspots). Instead, 14-km GWMF peaks in the midlatitudes near the $14-\mathrm{km}$ jet core (Fig. 11). However, the bands at $35^{\circ} \mathrm{S}$ and $45^{\circ} \mathrm{N}$ are to a large degree due to synoptic-scale waves. This can be seen by comparing to the GWMF at $18 \mathrm{~km}$ (cf. Figs. 10 and 11), where these bands are no longer prominent. The latitudinal offset in the GWMF peaks between 14,18 , and $30 \mathrm{~km}$ is consistent with meridional convergence of GWMF into the jet core of the polar vortex (Fig. 4), an effect that classical GW parameterizations would miss, as most of them ignore lateral propagation.

The relative contribution of orographic versus other sources to the zonal-mean GWMF is difficult to estimate from the logarithmic color scale of the maps shown in Figs. 5, 6, 9, and 10. Therefore, Figs. 12a and 12b show GWMF at $30 \mathrm{~km}$ averaged between $50^{\circ}$ and $60^{\circ} \mathrm{S}$ as a function of longitude. At $50^{\circ}-60^{\circ} \mathrm{S}$ the Andes at $75^{\circ} \mathrm{W}$ are the most important topographic obstacle (Fig. 12b). Furthermore, there are groups of small islands at $36.5^{\circ} \mathrm{W}$ (South Georgia) and $73.5^{\circ} \mathrm{E}$ (Kerguelen and Heard). Small islands may be a missing source of drag for the Southern Hemisphere circulation in GCMs with coarse grids (Alexander and Grimsdell 2013; Hoffmann et al. 2016). Differences between the profiles from HIRDLS and SABER mainly result from HIRDLS's ability to sample shorter horizontal wavelengths at $40^{\circ}-$ $63^{\circ} \mathrm{S}$ due to its favorable observational geometry at these latitudes. This captures accordingly a larger part of the GWMF spectrum. Furthermore, for SABER a broader latitude box $\left(20^{\circ}\right)$ was used for averaging than for HIRDLS $\left(5^{\circ}\right)$ when the GRACILE climatology was created (section 2 ), which would additionally blur narrow peaks.

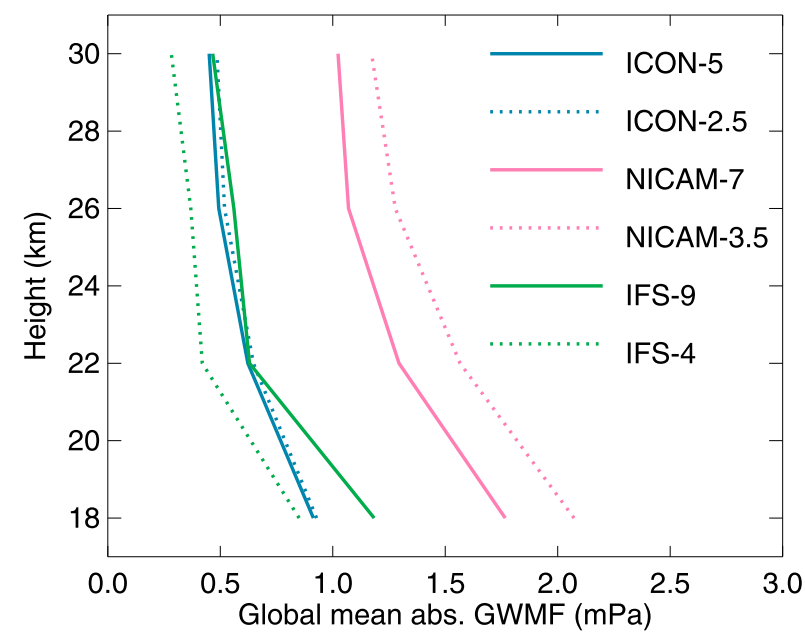

FIG. 8. Vertical profiles of WTQ-derived global-mean absolute GWMF for all simulations.

For each of the six simulations, WTQ and S3D show good overall agreement on the shape of the longitudinal profiles. But unlike S3D, WTQ produces stronger systematic offsets between different models. WTQ GWMFs in IFS are usually greater than in NICAM, which in turn are greater than in ICON, as was also found for the zonalmean GWMFs (Fig. 2b).

The Andes and the islands at $36.5^{\circ} \mathrm{W}$ have a visible S3D signature in all simulations (Fig. 12a). The S3Dderived Andean peaks are of similar magnitude in IFS-9, IFS-4, NICAM-7, and NICAM-3.5, but oceanic longitudes contribute more heavily to the zonal-mean GWMF in NICAM-7 and NICAM-3.5 relative to IFS-9 and IFS-4 (Fig. 12a). Thus, the contribution from the storm track is key for the greater zonal-mean S3D GWMF in NICAM compared to IFS at $50^{\circ}-60^{\circ} \mathrm{S}$. The latter also holds for WTQ. In ICON-5 and ICON-2.5, the Andean peaks in S3D are of similar magnitude as the GWMF along the Eastern Hemisphere storm track. Surprisingly, in WTQ there is no notable GWMF peak near the Andes in ICON-2.5. The 30-km WTQ global maps confirm the absence of the Andean peak in ICON2.5 (Fig. 6).

There are at least three potential explanations for the weaker Andean peak in ICON, particularly in ICON2.5 , relative to the other simulations: 1 ) a different nearsurface flow close to the Andes; 2) a different tendency for air to be lifted over a mountain versus flowing around the mountain (this possibility is only plausible because topography in ICON is better resolved than in IFS; see Fig. 1 in Stevens et al. 2019, manuscript submitted to Prog. Earth Planet. Sci.); and 3) different propagation, refraction, or filtering between the source and $30 \mathrm{~km}$. Figure 9 shows that at $14-\mathrm{km}$ GWMF along the Andes is 


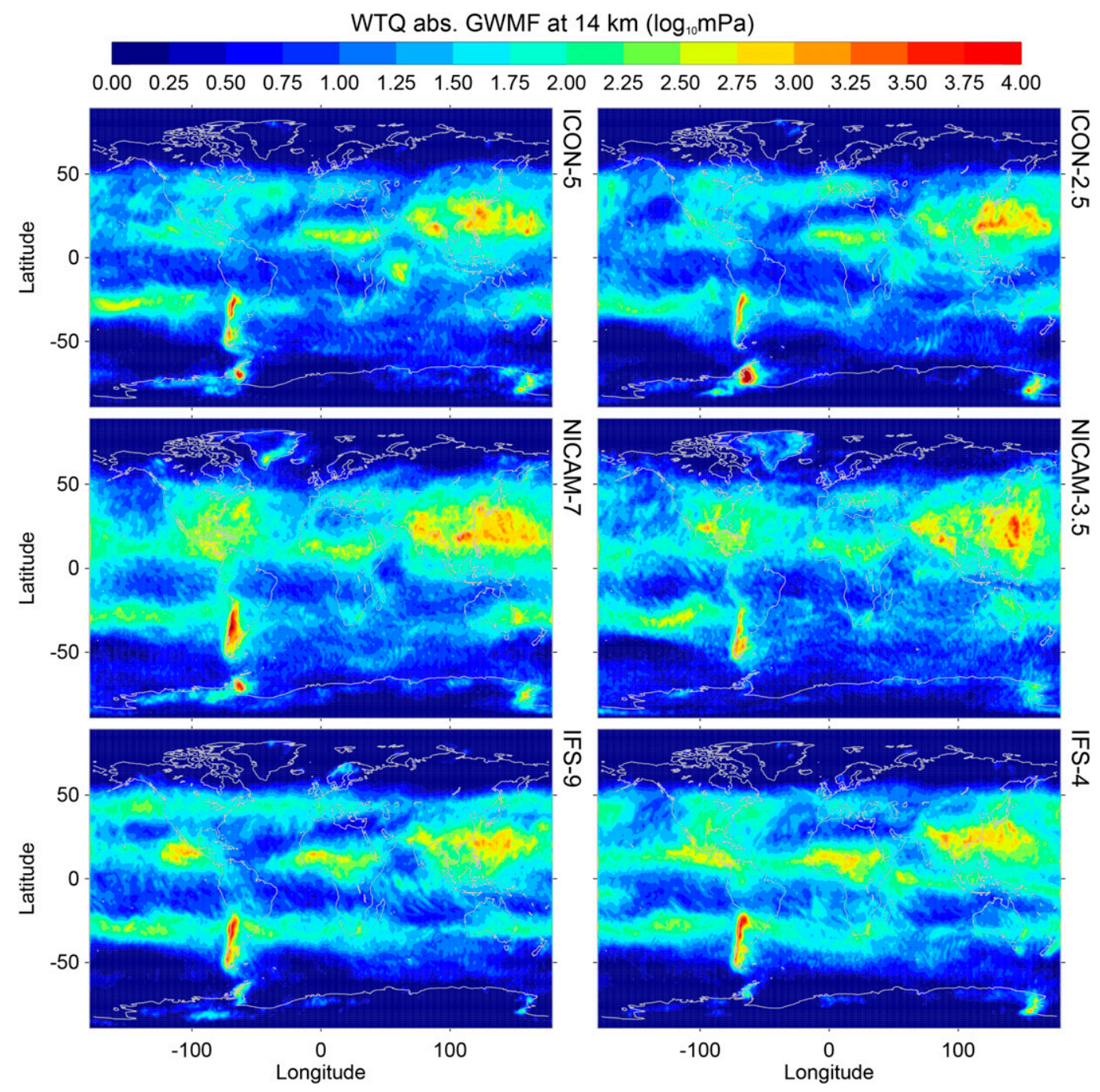

FIG. 9. August-mean absolute GWMF at $14 \mathrm{~km}$ for all simulations derived from WTQ.

slightly weaker in ICON than in the other simulations, even though NICAM-3.5 also shows weak GWMF at $14 \mathrm{~km}$. Thus, while 1 and 2 may both play a role, 3 is perhaps the dominant mechanism. The $14-\mathrm{km}$ zonal winds support this argument (Fig. 11): in IFS-4 and IFS-9 the 14-km jet core is located across southern South America; in NICAM-3.5 and NICAM-7 the jet core is located near Cape Horn. ICON, especially ICON-2.5, in contrast, shows a wind minimum over southern South America, which could be less favorable for the abovementioned meridional convergence of GWMF into the jet core of the polar vortex.

Here we have only speculated about the physical mechanisms, as investigating them in greater detail would require a dedicated study and is beyond the scope of this paper. Nevertheless, the disagreement between the models in terms of orographic waves emphasizes that orographic source strength may vary substantially between different models or different resolutions because there are ample factors that influence the orographic waves, some of which may themselves be affected by orographic GW drag, such as the mean near-surface wind.

\section{d. Comparison to AIRS}

We have only compared simulated S3D-derived GWMF to HIRDLS and SABER, as GWMF from HIRDLS and SABER is derived with a similar method, allowing for a quantitative comparison of observations and S3D results. On account of the uncertainties of this comparison (see section 2) the S3D GWMF of any of the simulations could be realistic. Yet our analysis so far has also shown that the agreement between simulations is better with respect to S3D than with respect to WTQ, where a quantitative comparison to observations is not 


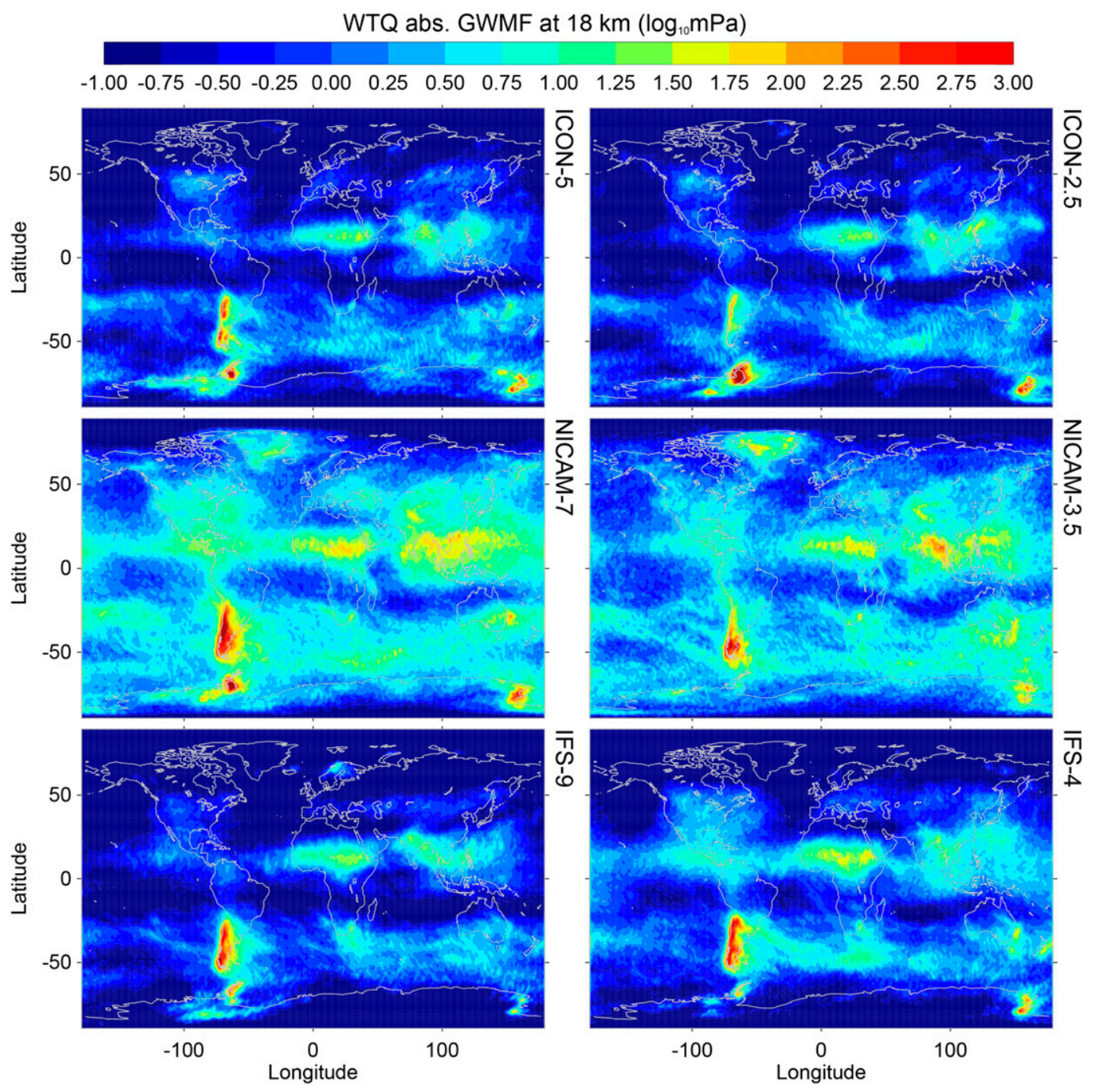

FIG. 10. August-mean absolute GWMF at $18 \mathrm{~km}$ for all simulations derived from WTQ.

possible. WTQ yields a maximum estimate of the GWMF without imposing restrictions on $\lambda_{z}$. It is desirable to also compare an integrated measure of the simulated GWMF. Therefore, we next present a comparison of simulated temperature perturbation amplitudes to those from the AIRS climatology (described in section 2).

To produce fields that are comparable to the AIRS climatology we perform the following steps on simulated temperatures: as the size of an AIRS footprint already corresponds well to the horizontal resolution of our data, as the first step we apply the AIRS weighting function to simulated vertical profiles of temperatures. Because model data are not available above $40 \mathrm{~km}$ this integral includes only $\sim 60 \%$ of the kernel function. We scale the resulting convolution to $100 \%$, which could cause significant overestimates of temperature variances in the simulations. For instance, if a wave was in its positive phase below $40 \mathrm{~km}$ and in its negative phase above $40 \mathrm{~km}$, then the integral could be zero in observations, but any value $>0$ in our model estimation. We next perform the same steps that were undertaken to obtain the AIRS climatology: the mean and a fourthorder polynomial are removed from $1800-\mathrm{km}$ longitudinal sections before variances are computed across $4^{\circ} \times 2^{\circ}$ sections in longitude and latitude. The result is shown in Fig. 13.

We again recognize the three subtropical peaks over the Caribbean Sea, Africa, and southern Asia and the northwest Pacific in all simulations and in AIRS. The spatial structure of temperature variances in the Southern Hemisphere mid- to high latitudes also shows a high resemblance to AIRS observations in all simulations. Thus, the high degree of realism that we documented in the 


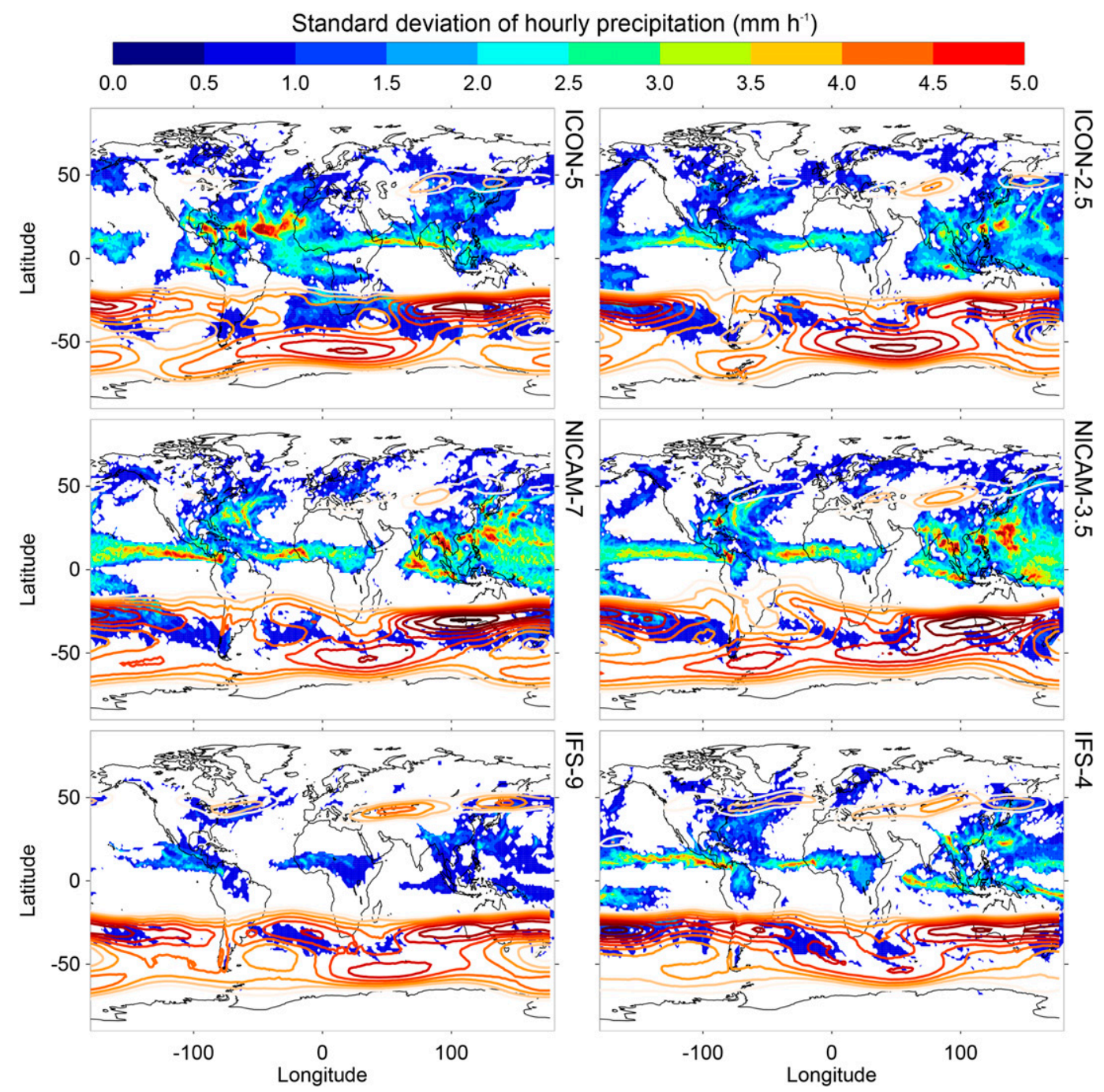

FIG. 11. Standard deviation of $0.1^{\circ} \times 0.1^{\circ}$ hourly surface precipitation (color shading) and zonal wind speed at $14 \mathrm{~km}$ (contours at $4 \mathrm{~m} \mathrm{~s}^{-1}$ intervals from 20 to $60 \mathrm{~m} \mathrm{~s}^{-1}$ ).

comparison to limb sounder observations is confirmed in this comparison to a nadir viewing instrument. Figure 13 also suggests that orographic waves from the Andes may be slightly too weak in ICON. In contrast, ICON shows strong waves from the Antarctic Peninsula, which were also seen in Fig. 5. Temperature variances in NICAM are greater than in ICON and IFS, which is in line with the zonal-mean S3D and WTQ GWMF (Fig. 2) and also supported by the greater power of temperature variances in NICAM (Fig. 1).

\section{Summary and conclusions}

We intercompared six global convection-permitting simulations of 1-month length initialized 1 August 2016 with respect to their global patterns of GWMF. The set of six simulations consists of two runs of NICAM (horizontal grid spacings of 7 and $3.5 \mathrm{~km}$, respectively), two runs of ICON ( 5 and $2.5 \mathrm{~km}$ ), and two runs of IFS ( 9 and $4 \mathrm{~km})$. The GWMF was analyzed using two different techniques: (i) three-dimensional sinusoidal wave fits (S3D) and (ii) a calculation based on the local values of wind and temperature quadratics (WTQ). In general, choices in numerics, horizontal and vertical resolution, divergence damping, subgrid turbulence, different filters, and the representation of orography may affect GWMF in models resolving GWs. We aimed to determine the differences between the models, the effects of changing the resolution between simulations of the same model and how results compare between the S3D and WTQ methods. In the following we give a summary of the most important results. 

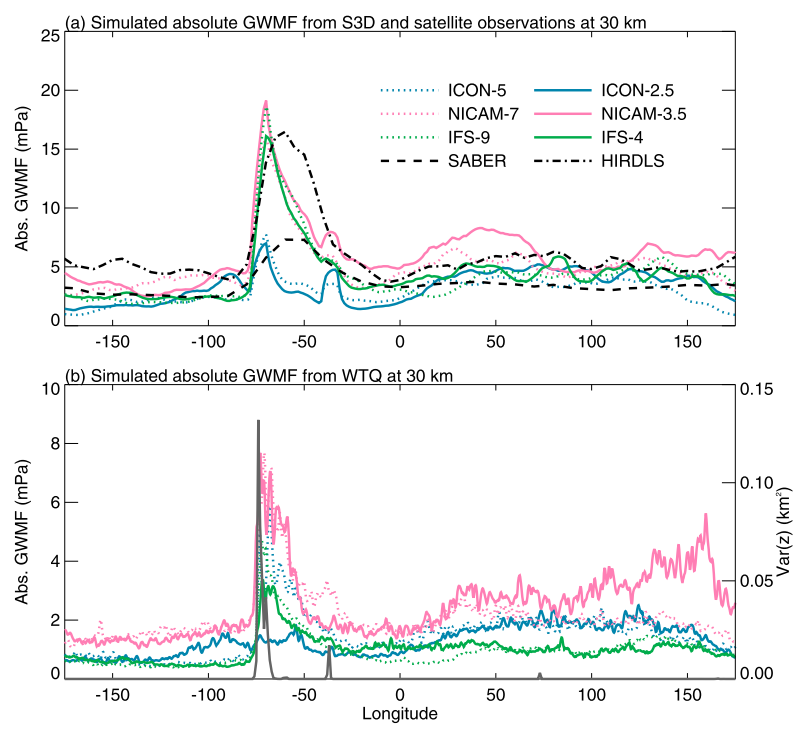

FIG. 12. (a) August-mean longitudinal distribution of absolute GWMF averaged between $50^{\circ}$ and $60^{\circ} \mathrm{S}$ at $30 \mathrm{~km}$ for all simulations and observed by HIRDLS and SABER. Simulated GWMF is computed by applying (a) S3D and (b) WTQ. The right-hand axis in (b) is the variance of surface elevation computed every $1^{\circ}$ longitude between $50^{\circ}$ and $60^{\circ} \mathrm{S}$ from ETOPO1 data (Amante and Eakins 2009 ) on a $0.017^{\circ} \times 0.033^{\circ}$ longitude-latitude grid (gray line)

\section{a. General differences}

NICAM simulations contain the most power for $\lambda_{h} \gtrsim$ $140 \mathrm{~km}$ (Fig. 1). A comparison of the simulations in terms of AIRS-observed temperature variances also shows that temperature variances are globally larger in NICAM than in ICON or IFS (Fig. 13). Only the two simulations of ICON have similar power spectra across all $\lambda_{h}$ without excessive damping at short $\lambda_{h}$ (Fig. 1). Vertical profiles of global-mean absolute GWMF show that GWMFs decrease at similar rates in all simulations (Fig. 8). Across the models, neither S3D nor WTQ show evidence for a systematic effect of resolution. The effects of changes in resolution on GWMFs simulated by the same model depend on the generation mechanism.

\section{b. Northern Hemisphere convection}

Differences in convective strength may help explain differences in the GWMF between simulations of the same model and between models at $0^{\circ}-40^{\circ} \mathrm{N}$. In ICON and IFS-9 the zonal-mean 30-km GWMFs in the Northern Hemisphere midlatitudes associated with dominant GWs of $\lambda_{z} \sim O(10) \mathrm{km}$ and $\lambda_{h} \sim(100-1000) \mathrm{km}$ are generally slightly weaker or similar to observations by the satellite limb sounders HIRDLS and SABER, whereas those of NICAM and IFS-4 are generally larger than observed. ICON-2.5 also shows the most realistic distribution of precipitation strengths at $0^{\circ}-40^{\circ} \mathrm{N}$ when compared to
TRMM (Fig. 7), although TRMM variances may be underestimated (Tan and Duan 2017). Unlike ICON and IFS, which do not use any convective parameterization, IFS switches from parameterizing shallow, midlevel, and deep convection in IFS-9 to parameterizing only shallow convection in IFS-4. Thus, for IFS, effects of resolution are not as neatly separable from effects of model formulation.

\section{c. Southern Hemisphere storm track and the Andes Mountains}

In the Southern Hemisphere most simulations produce peaks of 14-km GWMF near the southern tip of the Andes and near the Antarctic Peninsula that stem from orographically generated waves (Fig. 9). If we consider the leading wave at $30 \mathrm{~km}$ (i.e., S3D), then the Andean peaks are of similar magnitude in IFS-9, IFS-4, NICAM-7, and NICAM-3.5 (Fig. 12). At the same latitude, GWMFs away from orography are greater in NICAM-7 and NICAM-3.5 than in IFS-9 and IFS-4. As a result, zonalmean GWMFs at $50^{\circ}-60^{\circ} \mathrm{S}$ are greater in both NICAM-7 and NICAM-3.5 than in IFS-9 and IFS-4. The comparison of Southern Hemisphere WTQ GWMF between 14 and $30 \mathrm{~km}$ (Figs. 6 and 9) shows evidence for upward and southward propagation, focusing GWs into the jet core of the polar vortex. This is consistent with strong southward net meridional S3D GWMF at $50^{\circ} \mathrm{S}$ (Fig. 4).

Near the Andes S3D 30-km GWMFs in ICON-5 and ICON-2.5 are weaker than in NICAM and IFS, and ICON's GWMF magnitudes over orography are similar to those over the storm track away from orography (Fig. 12). The Andean peak in 30-km WTQ GWMFs is absent in ICON-2.5. These weak orographic wave signatures from the Andes in ICON are also found in the AIRS comparison of vertically integrated temperature variances. In contrast, GWMF from the Antarctic Peninsula is larger in ICON than in the other models. We argued that a combination of varying orographic wave excitement combined with different propagation characteristics due to weaker winds above the Andes, in particular in ICON-2.5, may explain the differences at $30 \mathrm{~km}$.

\section{d. Methodological differences}

Differences between the simulations of different models or at different resolutions are not as pronounced in S3D as they are in WTQ. The closer match of S3D GWMF can partly be attributed to focusing the analysis more strongly on a certain part of the GW spectrum. All simulations show excellent agreement in terms of their S3D-derived spectra of $\lambda_{h}$ and $\lambda_{z}$ (Fig. 3). Thus, the main factor that can cause discrepancies between the 


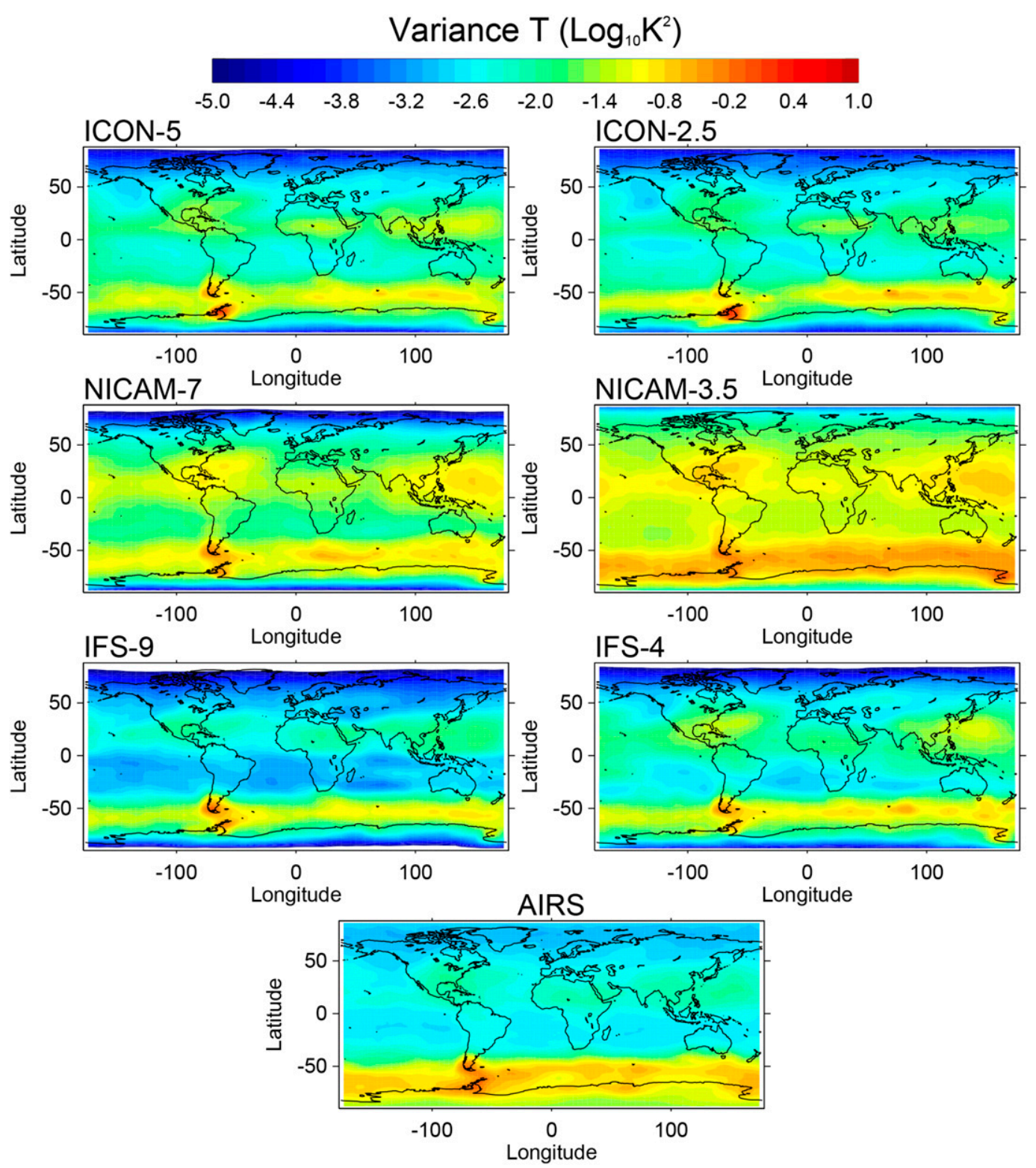

FIG. 13. August-mean simulated and AIRS-observed temperature variances. Simulated temperature perturbations between 20- and 40-km altitudes were processed to account for the AIRS's instrument sensitivity and observational geometry. Please see the text for further information.

S3D results of different simulations are GW amplitudes. Generally, we found a very good qualitative agreement between S3D and WTQ. This is not self-evident given that the two methods are very different in that S3D is based on only the temperature field and focuses on the dominant wave, whereas WTQ is based on temperatures and three-dimensional winds

Given that none of the simulations considered here was specifically designed to produce realistic GWs, it is promising that they all show detailed observed GWMF features. Clearly, our comparisons to observations are limited by large uncertainties and the fact that each instrument can only observe a certain fraction of the $\mathrm{GW}$ spectrum. We did not investigate GWs of short horizontal wavelengths, which likely make an important contribution to the total GWMF. Nevertheless, it would be worthwhile to examine waves of short scales in individual models. This task may also require different observations as the observational instruments described here cannot observe waves of very short horizontal as well as vertical wavelengths. We showed here that even at wavelengths that largely exceed the model grid spacing, 
differences in GWMFs can be noted that depend on resolution as well as on model formulation. Thus, while running GCMs at convection-permitting or even convection-resolving scales may free us from cumbersome GW parameterizations, it will remain a difficult challenge to validate the realism of simulated GWs.

Acknowledgments. The work of C. C. Stephan and H. Schmidt was supported by the Deutsche Forschungsgemeinschaft (DFG; German Research Foundation) Project SCHM 2158/5-2, which is part of the DFG researcher group FOR 1898 (MS-GWaves). The work of M. Ern, P. Preusse, and C. Strube was supported by the DFG Projects ER 474/4-2 and PR 919/4-2 (MS-GWaves/SV), which are also part of MS-GWaves. The GPM IMERG Final Precipitation data were provided by the NASA Goddard Space Flight Center's Precipitation Processing System, which develop and compute the GPM IMERG Final Precipitation as a contribution to the Global Precipitation Measurement (GPM) mission, and are archived at the NASA GES DISC (https://doi.org/ 10.5067/GPM/IMERG/3B-MONTH/05). The GRACILE dataset is available online (https://doi.org/10.1594/ PANGAEA.879658). Data from numerical simulations are stored by the Excellence in Science of Weather and Climate in Europe (ESiWACE) project at the German Climate Computing Center (DKRZ) and can be made available upon request. We thank the NICAM group, in particular Masaki Satoh, Chihiro Kodama, and Ryosuke Shibuya, and the IFS group, in particular Peter Düben and Nils Wedi, for providing the data from their simulations. We thank the HIRDLS and SABER instrument teams for creating and maintaining the satellite datasets. HIRDLS level-2 data are freely available via the NASA Goddard Earth Sciences Data and Information Services Center (GES DISC; http://disc.sci.gsfc.nasa.gov/Aura). SABER data are provided by GATS, Inc. (freely available at http://saber.gats-inc.com/). AIRS data are distributed by the NASA GES DISC (https://airs.jpl.nasa.gov/data/get_data).

\section{REFERENCES}

Alexander, M. J., and K. H. Rosenlof, 1996: Nonstationary gravity wave forcing of the stratospheric zonal mean wind. J. Geophys. Res., 101, 23 465-23 474, https://doi.org/10.1029/ 96JD02197.

, and A. W. Grimsdell, 2013: Seasonal cycle of orographic gravity wave occurrence above small islands in the Southern Hemisphere: Implications for effects on general circulation. J. Geophys. Res. Atmos., 118, 11 589-11 599, https://doi.org/ 10.1002/2013JD020526.

, and Coauthors, 2010: Recent developments in gravity-wave effects in climate models and the global distribution of gravity-wave momentum flux from observations and models. Quart. J. Roy. Meteor. Soc., 136, 1103-1124, https://doi.org/10.1002/qj.637.
Amante, C., and B. W. Eakins, 2009: ETOPO1 1 arc-minute global relief model: Procedures, data sources and analysis. NOAA Tech. Memo. NESDIS NGDC-24, 25 pp., https://doi.org/ 10.7289/V5C8276M.

Baldwin, M., and Coauthors, 2001: The quasi-biennial oscillation. Rev. Geophys., 39, 179-229, https://doi.org/10.1029/1999RG000073.

Bechtold, P., M. Köhler, T. Jung, F. Doblas-Reyes, M. Leutbecher, M. Rodwell, F. Vitart, and G. Balsamo, 2008: Advances in simulating atmospheric variability with the ECMWF model: From synoptic to decadal time-scales. Quart. J. Roy. Meteor. Soc., 134, 1337-1351, https://doi.org/10.1002/qj.289.

Beres, J. H., M. J. Alexander, and J. R. Holton, 2004: A method of specifying the gravity wave spectrum above convection based on latent heating properties and background wind. J. Atmos. Sci., 61, 324-337, https://doi.org/10.1175/15200469(2004)061<0324:AMOSTG>2.0.CO;2.

—, R. R. Garcia, B. A. Boville, and F. Sassi, 2005: Implementation of a gravity wave source spectrum parameterization dependent on the properties of convection in the Whole Atmosphere Community Climate Model. J. Geophys. Res., 110, D10108, https://doi.org/10.1029/2004JD005504.

Björn, L. G., 1984: The cold summer mesopause. Adv. Space Res., 4, 145-151, https://doi.org/10.1016/0273-1177(84)90277-1.

Callies, J., O. Bühler, and R. Ferrari, 2016: The dynamics of mesoscale winds in the upper troposphere and lower stratosphere. J. Atmos. Sci., 73, 4853-4872, https://doi.org/10.1175/JAS-D-160108.1.

Charron, M., and E. Manzini, 2002: Gravity waves from fronts: Parameterization and middle atmosphere response in a general circulation model. J. Atmos. Sci., 59, 923-941, https://doi.org/10.1175/1520-0469(2002)059<0923:GWFFPA> 2.0.CO;2.

Choi, H.-J., and H.-Y. Chun, 2011: Momentum flux spectrum of convective gravity waves. Part I: An update of a parameterization using mesoscale simulations. J. Atmos. Sci., 68, 739-759, https://doi.org/10.1175/2010JAS3552.1.

,-- J. Gong, and D. L. Wu, 2012: Comparison of gravity wave temperature variances from ray-based spectral parameterization of convective gravity wave drag with AIRS observations. J. Geophys. Res., 117, D05115, https://doi.org/ 10.1029/2011JD016900.

Dörnbrack, A., M. Leutbecher, R. Kivi, and E. Kyrö, 1999: Mountain-wave-induced record low stratospheric temperatures above northern Scandinavia. Tellus, 51A, 951-963, https:// doi.org/10.3402/tellusa.v51i5.14504.

Eckermann, S. D., and P. Preusse, 1999: Global measurements of stratospheric mountain waves from space. Science, 286, 15341537, https://doi.org/10.1126/science.286.5444.1534.

Ern, M., P. Preusse, M. J. Alexander, and C. D. Warner, 2004: Absolute values of gravity wave momentum flux derived from satellite data. J. Geophys. Res., 109, D20103, https://doi.org/ 10.1029/2004JD004752.

,,-- J. C. Gille, C. L. Hepplewhite, M. G. Mlynczak, J. M. Russell III, and M. Riese, 2011: Implications for atmospheric dynamics derived from global observations of gravity wave momentum flux in stratosphere and mesosphere. J. Geophys. Res., 116, D19107, https://doi.org/10.1029/2011JD015821.

_ L. Hoffmann, and P. Preusse, 2017: Directional gravity wave momentum fluxes in the stratosphere derived from highresolution AIRS temperature data. Geophys. Res. Lett., $\mathbf{4 4}$ 475-485, https://doi.org/10.1002/2016GL072007.

_ Q. T. Trinh, P. Preusse, J. C. Gille, M. G. Mlynczak, J. M. Russell III, and M. Riese, 2018: GRACILE: A comprehensive 
climatology of atmospheric gravity wave parameters based on satellite limb soundings. Earth Syst. Sci. Data, 10, 857-892, https://doi.org/10.5194/essd-10-857-2018.

Fritts, D. C., and Coauthors, 2016: The Deep Propagating Gravity Wave Experiment (DEEPWAVE): An airborne and groundbased exploration of gravity wave propagation and effects from their sources throughout the lower and middle atmosphere. Bull. Amer. Meteor. Soc., 97, 425-453, https://doi.org/ 10.1175/BAMS-D-14-00269.1.

Garcia, R. R., and S. Solomon, 1985: The effect of breaking gravity waves on the dynamics and chemical composition of the mesosphere and lower thermosphere. J. Geophys. Res., 90, 38503868, https://doi.org/10.1029/JD090iD02p03850.

— , A. K. Smith, D. E. Kinnison, A. de la Camara, and D. J. Murphy, 2017: Modification of the gravity wave parameterization in the Whole Atmosphere Community Climate Model: Motivation and results. J. Atmos. Sci., 74, 275-291, https:// doi.org/10.1175/JAS-D-16-0104.1.

Gelaro, R., and Coauthors, 2015: Evaluation of the $7 \mathrm{~km}$ GEOS-5 nature run. NASA Tech. Rep. NASA/TM-2014-104606, Vol. $36,305 \mathrm{pp}$.

Geller, M. A., and Coauthors, 2013: A comparison between gravity wave momentum fluxes in observations and climate models. J. Climate, 26, 6383-6405, https://doi.org/10.1175/JCLI-D-1200545.1.

Grimsdell, A. W., M. J. Alexander, P. T. May, and L. Hoffmann, 2010: Model study of waves generated by convection with direct validation via satellite. J. Atmos. Sci., 67, 1617-1631, https://doi.org/10.1175/2009JAS3197.1.

Hines, C. O., 1997: Doppler-spread parameterization of gravitywave momentum deposition in the middle atmosphere. Part 1: Basic formulation. J. Atmos. Sol. Terr. Phys., 59, 371-386, https://doi.org/10.1016/S1364-6826(96)00079-X.

Hoffmann, L., and M. J. Alexander, 2010: Occurrence frequency of convective gravity waves during the North American thunderstorm season. J. Geophys. Res., 115, D20111, https:// doi.org/10.1029/2010JD014401.

__, X. Xue, and M. J. Alexander, 2013: A global view of stratospheric gravity wave hotspots located with Atmospheric Infrared Sounder observations. J. Geophys. Res. Atmos., 118, 416-434, https://doi.org/10.1029/2012JD018658.

—, M. J. Alexander, C. Clerbaux, A. W. Grimsdell, C. I. Meyer, T. Rößler, and B. Tournier, 2014: Intercomparison of stratospheric gravity wave observations with AIRS and IASI. Atmos. Meas. Tech., 7, 4517-4537, https://doi.org/10.5194/amt7-4517-2014.

—, A. W. Grimsdell, and M. J. Alexander, 2016: Stratospheric gravity waves at Southern Hemisphere orographic hotspots: 2003-2014 AIRS/Aqua observations. Atmos. Chem. Phys., 16, 9381-9397, https://doi.org/10.5194/acp-16-9381-2016.

Holt, L. A., M. J. Alexander, L. Coy, C. Liu, A. Molod, W. Putmanb, and S. Pawsonb, 2017: An evaluation of gravity waves and gravity wave sources in the Southern Hemisphere in a $7 \mathrm{~km}$ global climate simulation. Quart. J. Roy. Meteor. Soc., 143, 2481-2495, https://doi.org/10.1002/qj.3101.

Holton, J. R., 1982: The role of gravity wave induced drag and diffusion in the momentum budget of the mesosphere. J. Atmos. Sci., 39, 791-799, https://doi.org/10.1175/1520-0469(1982) 039<0791:TROGWI >2.0.CO;2.

, 1983: The influence of gravity wave breaking on the general circulation of the middle atmosphere. J. Atmos. Sci., 40, 24972507, https://doi.org/10.1175/1520-0469(1983)040<2497: TIOGWB $>2.0 . \mathrm{CO} ; 2$.
Huffman, G., 2017: GPM IMERG final precipitation L3 1 month 0.1 degree $\times 0.1$ degree, version 05 . Goddard Earth Sciences Data and Information Services Center, accessed 21 August 2018, https://doi.org/10.5067/GPM/ IMERG/3B-MONTH/05.

Jeevanjee, N., 2017: Vertical velocity in the gray zone. $J . A d v$. Model. Earth Syst., 9, 2304-2316, https://doi.org/10.1002/ 2017MS001059.

Jia, J. Y., P. Preusse, M. Ern, H. Y. Chun, J. C. Gille, S. D. Eckermann, and M. Riese, 2014: Sea surface temperature as a proxy for convective gravity wave excitation: A study based on global gravity wave observations in the middle atmosphere. Ann. Geophys., 32, 1373-1394, https://doi.org/10.5194/angeo32-1373-2014.

Jiang, J. H., S. D. Eckermann, D. L. Wu, and J. Ma, 2004: A search for mountain waves in MLS stratospheric limb radiances from the winter Northern Hemisphere: Data analysis and global mountain wave modeling. J. Geophys. Res., 109, D03107, https://doi.org/10.1029/2003JD003974.

Kang, M.-J., H.-Y. Chun, and Y.-H. Kim, 2017: Momentum flux of convective gravity waves derived from an offline gravity wave parameterization. Part I: Spatiotemporal variations at source level. J. Atmos. Sci., 74, 3167-3189, https://doi.org/10.1175/ JAS-D-17-0053.1.

Kim, S.-Y., H.-Y. Chun, and J.-J. Baik, 2007: Sensitivity of typhoon-induced gravity waves to cumulus parameterizations. Geophys. Res. Lett., 34, L15814, https://doi.org/10.1029/ $2007 \mathrm{GL} 030592$.

Kim, Y., A. C. Bushell, D. R. Jackson, and H. Y. Chun, 2013: Impacts of introducing a convective gravity-wave parameterization upon the QBO in the Met Office Unified Model. Geophys. Res. Lett., 40, 1873-1877, https://doi.org/10.1002/ grl.50353.

Klemp, J. B., J. Dudhia, and A. D. Hassiotis, 2008: An upper gravity-wave absorbing layer for NWP applications. Mon. Wea. Rev., 136, 3987-4004, https://doi.org/10.1175/2008MWR2596.1.

Koshyk, J. N., and K. Hamilton, 2001: The horizontal kinetic energy spectrum and spectral budget simulated by a high-resolution troposphere-stratosphere-mesosphere GCM. J. Atmos. Sci., 58, 329-348, https://doi.org/10.1175/1520-0469(2001)058<0329: THKESA $>2.0 . \mathrm{CO} ; 2$.

Krisch, I., and Coauthors, 2017: First tomographic observations of gravity waves by the infrared limb imager GLORIA. Atmos. Chem. Phys., 17, 14 937-14 953, https://doi.org/10.5194/acp-1714937-2017.

Labitzke, K., 2005: On the solar cycle-QBO relationship: A summary. J. Atmos. Sol. Terr. Phys., 67, 45-54, https://doi.org/ 10.1016/j.jastp.2004.07.016.

Lehmann, C. I., Y.-H. Kim, P. Preusse, H.-Y. Chun, M. Ern, and S.-Y. Kim, 2012: Consistency between Fourier transform and small-volume few-wave decomposition for spectral and spatial variability of gravity waves above a typhoon. Atmos. Meas. Tech., 5, 1637-1651, https://doi.org/10.5194/amt-5-16372012.

Lilly, D. K., and P. J. Kennedy, 1973: Observations of a stationary mountain wave and its associated momentum flux and energy dissipation. J. Atmos. Sci., 30, 1135-1152, https://doi.org/ 10.1175/1520-0469(1973)030<1135:OOASMW >2.0.CO;2.

Liu, H.-L., J. M. McInerney, S. Santos, P. H. Lauritzen, M. A. Taylor, and N. M. Pedatella, 2014: Gravity waves simulated by high-resolution Whole Atmosphere Community Climate Model. Geophys. Res. Lett., 41, 9106-9112, https://doi.org/ 10.1002/2014GL062468. 
Lott, F., and M. J. Miller, 1997: A new subgrid-scale orographic drag parametrization: Its formulation and testing. Quart. J. Roy. Meteor. Soc., 123, 101-127, https://doi.org/10.1002/ qj.49712353704.

Malardel, S., N. Wedi, W. Deconinck, M. Diamantakis, C. Kuehnlein, G. Mozdzynski, M. Hamrud, and P. Smolarkiewicz, 2016: A new grid for the IFS. ECMWF Newsletter, No. 146, ECMWF, Reading, United Kingdom, 23-28.

Manzini, E., and N. A. McFarlane, 1998: The effect of varying the source spectrum of a gravity wave parameterization in a middle atmosphere general circulation model. J. Geophys. Res., 103, 31 523-31 539, https://doi.org/10.1029/98JD02274.

Marshall, A. G., and A. A. Scaife, 2009: Impact of the QBO on surface winter climate. J. Geophys. Res., 114, D18110, https:// doi.org/10.1029/2009JD011737.

McFarlane, N. A., 1987: The effect of orographically excited gravity wave drag on the general circulation of the lower stratosphere and troposphere. J. Atmos. Sci., 44, 1775-1800, https://doi.org/10.1175/1520-0469(1987)044<1775:TEOOEG> 2.0.CO;2.

McLandress, C., M. J. Alexander, and D. L. Wu, 2000: Microwave Limb Sounder observations of gravity waves in the stratosphere: A climatology and interpretation. J. Geophys. Res., 105, 11 947-11 967, https://doi.org/10.1029/2000JD900097.

Müller, S. K., E. Manzini, M. A. Giorgetta, K. Sato, and T. Nasuno, 2018: Convectively generated gravity waves in high resolution models of tropical dynamics. J. Adv. Model. Earth Syst., 10, 2564-2588, https://doi.org/10.1029/2018MS001390.

Neale, R. B., and Coauthors, 2010: Description of the NCAR Community Atmospheric Model (CAM 4.0). NCAR Tech. Note NCAR/TN-485+STR, 212 pp., www.cesm.ucar.edu/ models/ccsm4.0/cam/docs/description/cam4_desc.pdf.

O'Sullivan, D., and T. J. Dunkerton, 1995: Generation of inertiagravity waves in a simulated life cycle of baroclinic instability. J. Atmos. Sci., 52, 3695-3716, https://doi.org/10.1175/15200469(1995)052<3695:GOIWIA > 2.0.CO;2.

Orr, A., P. Bechtold, J. Scinocca, M. Ern, and M. Janiskova, 2010: Improved middle atmosphere climate and forecasts in the ECMWF model through a nonorographic gravity wave drag parameterization. J. Climate, 23, 5905-5926, https://doi.org/ 10.1175/2010JCLI3490.1.

— cooling for the formation of PSCs over the Antarctic Peninsula in a chemistry-climate model. Atmos. Chem. Phys., 15, 1071-1086, https://doi.org/10.5194/acp-15-1071-2015.

Palmer, T. N., G. J. Shutts, and R. Swinbank, 1986: Alleviation of a systematic westerly bias in general circulation and numerical weather prediction models through an orographic gravity wave drag parametrization. Quart. J. Roy. Meteor. Soc., 112, 1001-1039, https://doi.org/10.1002/qj.49711247406.

Pfister, L., S. Scott, M. Loewenstein, S. Bowen, and M. Legg, 1993: Mesoscale disturbances in the tropical stratosphere excited by convection: Observations and effects on the stratospheric momentum budget. J. Atmos. Sci., 50, 1058-1075, https://doi.org/10.1175/1520-0469(1993)050<1058:MDITTS > 2.0.CO;2.

Plougonven, R., and F. Zhang, 2014: Internal gravity waves from atmospheric jets and fronts. Rev. Geophys., 52, 33-76, https:// doi.org/10.1002/2012RG000419.

Prein, A. F., and Coauthors, 2015: A review on regional convection-permitting climate modeling: Demonstrations, prospects, and challenges. Rev. Geophys., 53, 323-361, https:// doi.org/10.1002/2014RG000475.
Preusse, P., G. Eidmann, S. D. Eckermann, B. Schaeler, R. Spang, and D. Offermann, 2001: Indications of convectively generated gravity waves in CRISTA temperatures. Adv. Space Res., 27, 1653-1658, https://doi.org/10.1016/S0273-1177(01) 00231-9.

_ M. Ern, P. Bechtold, S. D. Eckermann, S. Kalisch, Q. T. Trinh, and M. Riese, 2014: Characteristics of gravity waves resolved by ECMWF. Atmos. Chem. Phys., 14, $10483-10508$, https://doi.org/10.5194/acp-14-10483-2014.

Richter, J. H., F. Sassi, and R. R. Garcia, 2010: Toward a physically based gravity wave source parameterization in a general circulation model. J. Atmos. Sci., 67, 136-156, https://doi.org/ 10.1175/2009JAS3112.1.

Sato, K., and M. Yoshiki, 2008: Gravity wave generation around the polar vortex in the stratosphere revealed by 3-hourly radiosonde observations at Syowa station. J. Atmos. Sci., 65, 3719-3735, https://doi.org/10.1175/2008JAS2539.1.

_, S. Watanabe, Y. Kawatani, Y. Tomikawa, K. Miyazaki, and M. Takahashi, 2009: On the origins of mesospheric gravity waves. Geophys. Res. Lett., 36, L19801, https://doi.org/10.1029/ 2009GL039908.

Satoh, M., T. Matsuno, H. Tomita, H. Miura, T. Nasuno, and S. Iga, 2008: Nonhydrostatic Icosahedral Atmospheric Model (NICAM) for global cloud resolving simulations. J. Comput. Phys., 227, 3486-3514, https://doi.org/10.1016/ j.jcp.2007.02.006.

_- , and Coauthors, 2014: The Non-Hydrostatic Icosahedral Atmospheric Model: Description and development. Prog. Earth Planet. Sci., 1, 18, https://doi.org/10.1186/s40645014-0018-1.

Scaife, A. A., N. Butchart, C. D. Warner, and R. Swinbank, 2002: Impact of a spectral gravity wave parameterization on the stratosphere in the Met Office Unified Model. J. Atmos. Sci., 59, 1473-1489, https://doi.org/10.1175/15200469(2002)059<1473:IOASGW>2.0.CO;2.

Scinocca, J. F., 2003: An accurate spectral nonorographic gravity wave drag parameterization for general circulation models. J. Atmos. Sci., 60, 667-682, https://doi.org/10.1175/ 1520-0469(2003)060<0667:AASNGW>2.0.CO;2.

Stephan, C. C., and M. J. Alexander, 2014: Summer season squall line simulations: Sensitivity of gravity waves to physics parameterization and implications for their parameterization in global climate models. J. Atmos. Sci., 71, 3376-3391, https:// doi.org/10.1175/JAS-D-13-0380.1.

_ and - 2015: Realistic simulations of atmospheric gravity waves over the continental U.S. using precipitation radar data. J. Adv. Model. Earth Syst., 7, 823-835, https://doi.org/10.1002/ 2014MS000396.

—_— from convection and implications for their parameterization in global circulation models. J. Atmos. Sci., 73, 2729-2742, https://doi.org/10.1175/JAS-D-15-0303.1.

— C. Strube, D. Klocke, M. Ern, L. Hoffmann, P. Preusse, and H. Schmidt, 2019: Gravity waves in global high-resolution simulations with explicit and parameterized convection. J. Geophys. Res. Atmos., 124, 4446-4459, https://doi.org/ 10.1029/2018JD030073.

Stockwell, R. G., L. Mansinha, and R. P. Lowe, 1996: Localization of the complex spectrum: The $\mathrm{S}$ transform. IEEE Trans. Signal Process., 44, 998-1001, https://doi.org/10.1109/78.492555.

Tan, M. L., and Z. Duan, 2017: Assessment of GPM and TRMM precipitation products over Singapore. Remote Sens., 9, 720, https://doi.org/10.3390/rs9070720. 
Watanabe, S., Y. Kawatani, Y. Tomikawa, K. Miyazaki, M. Takahashi, and K. Sato, 2008: General aspects of a T213L256 middle atmosphere general circulation model. J. Geophys. Res., 113, D12110, https://doi.org/10.1029/ 2008JD010026.

Wedi, N. P., 2014: Increasing horizontal resolution in numerical weather prediction and climate simulations: Illusion or panacea? Philos. Trans. Roy. Soc., 372A, 20130289, https://doi.org/ 10.1098/rsta.2013.0289.
Zängl, G., D. Reinert, P. Ripodas, and M. Baldauf, 2015: The ICON (Icosahedral Non-Hydrostatic) modelling framework of DWD and MPI-M: Description of the non-hydrostatic dynamical core. Quart. J. Roy. Meteor. Soc., 141, 563-579, https:// doi.org/10.1002/qj.2378.

Zhang, F., 2004: Generation of mesoscale gravity waves in uppertropospheric jet-front systems. J. Atmos. Sci., 61, 440-457, https://doi.org/10.1175/1520-0469(2004)061<0440:GOMGWI> 2.0.CO;2. 